\title{
Structural Analysis of Molds with Conformal Cooling Channels: A Numerical Study
}

Hugo Miguel Silva ( $\sim$ b7802@dep.uminho.pt )

DEP-Department of Polymer Engineering University of Minho

\section{Tiago Noversa}

DEP-Department of Polymer Engineering University of Minho

\section{Hugo Rodrigues}

DEP-Department of Polymer Engineering University of Minho

\section{Leandro Fernandes}

DEP-Department of Polymer Engineering University of Minho

\section{António Pontes}

DEP-Department of Polymer Engineering University of Minho

\section{Research Article}

Keywords: Structural analysis, Finite Element Method, ANSYS, Computer Aided Engineering

Posted Date: November 9th, 2021

DOI: https://doi.org/10.21203/rs.3.rs-1051523/v1

License: (c) (1) This work is licensed under a Creative Commons Attribution 4.0 International License.

Read Full License 
Noname manuscript No.

(will be inserted by the editor)

\title{
Structural analysis of molds with conformal cooling channels: a numerical study
}

\author{
Hugo Miguel Silva $\cdot$ Tiago Noversa • Hugo Rodrigues $・$ Leandro Fernandes · António \\ Pontes
}

\author{
IPC- Institute for Polymers and Composites \\ DEP-Department of Polymer Engineering University of Minho \\ Campus de Azurém 5100 - 061 Guimarães, Portugal \\ *corresponding author, email: b7802 @dep.uminho.pt
}

Received: date / Accepted: date

\begin{abstract}
The manufacturing of Conformal cooling channels (CCC's) is now easier and more affordable, owing to the recent developments in the field of additive manufacturing. The use of CCC's allows better cooling performances than the conventional (straight-drilled) channels, in the injection molding process. The main reason is that CCC's can follow the pathways of the molded geometry, while the conventional channels, manufactured by traditional machining techniques, are not able to. Using CCCs can significantly improve the cycle time, allow to obtain a more uniform temperature distribution, and reduce thermal stresses and warpage. However, the design process for CCC is more complex than for conventional channels. Computer-aided engineering (CAE) simulations are important for achieving effective and affordable design. This article presents important results regarding molds with new conformal cooling channels geometries. The aim is to assess the maximum pressure that the parts can be subjected to in a real injection molding application. Linear structural analyses are carried over in the Finite Element Method Software
\end{abstract}


ANSYS Workbench 2020 R2, in order to analyze both the resistance and stiffness behavior of the studied geometries. The results are analyzed according to several metrics. The results were discussed and it could be concluded that some of the structures are suitable for the typical operating conditions of the injection molding process.

Keywords: Structural analysis; Finite Element Method, ANSYS; Computer Aided Engineering;

Hugo Miguel Silva

IPC Institute for Polymers and Composites DEP Department of Polymer Engineering,

University of Minho, Campus de Azurém, 5100 - 061, Guimarães, Portugal

Tiago Noversa

IPC Institute for Polymers and Composites DEP Department of Polymer Engineering, University of Minho, Campus de Azurém, 5100 - 061, Guimarães, Portugal

Leandro Fernandes

IPC Institute for Polymers and Composites DEP Department of Polymer Engineering, University of Minho, Campus de Azurém, 5100 - 061, Guimarães, Portugal

Hugo Rodrigues

IPC Institute for Polymers and Composites DEP Department of Polymer Engineering, University of Minho, Campus de Azurém, 5100 - 061, Guimarães, Portugal António Pontes

IPC Institute for Polymers and Composites DEP Department of Polymer Engineering, University of Minho, Campus de Azurém, 5100 - 061, Guimarães, Portugal 


\section{Introduction}

A cellular solid is a solid whose mass is lower than its bulk version, considering the same global dimensions, i.e.length, width and height. The Young's modulus is very important for the mechanical behavior, as it is the most relevant measure of the material's stiffness. The Young's modulus of a cellular solid is reduced by the same fraction as its relative density, i.e., density related to the bulk solid. The geometries of the cooling channels studied in this work can be considered as cellular solids. These are embedded in a mold, with typical dimensions for an injection molding machine. When analyzing a bulk part, the mechanical behavior can be accurately determined analytically, if the shape is simple. [1]. For some regular cellular solids, such as honeycombs and foams, some analytical models were already developed [1]. However, the models are only valid for the specific geometries under study and can't be generalized anyhow. If one considers thin-walled solids, there are additional effects, in relation to bulk geometries. Timoshenko described the effect of shear deformation on the bending stiffness. However, for shapes of higher complexity, there is an influence of unknown factors, which makes any analytical equation to originate low accuracy when comparing to numerical and/or experimental results. Although numerical results are always approximated and may, in some cases, originate significant errors [2], they are the most economically feasible solution for obtaining results if several geometries/parts are to be analyzed. Much research has been done in the field of design and modeling of CCCs in injection molds. Various simulation packages have been used to analyze mold and channel designs. In 2005, Moldflow analysis was used in I-DEAS ${ }^{\mathrm{TM}}$ by Dimla et al. to find the best position of the channel [3]. ABM Saifullah and SH Masood analyzed the "part cooling time" 
using ANSYS thermal analysis software [4]. In 2009, the same research group used MPI simulation software to analyze parts and compared the results for conventional and quadratic CCC profiles; they concluded that conformal channels have 38\% shorter cooling time than conventional channels [5]. Gloinn et al. from Ireland performed a FEM analysis to determine the mold temperature using ABS polymer as the molten material and cooling water inlet [6]. Another study was conducted in 2007 by [7] using Moldflow Plastic Insight 3.1 to investigate the thermal effects of cooling channel design on the injection molding process. The authors proposed a novel framework for the design of a uniform CC. Using the same simulation software, Wang et al. verified the advantages of a cooling loop; they modeled only the part temperature [8]. In 2017, the comparative effect of conventional, serial, parallel, and additiveparallel cooling channels was studied by Khan et al. in terms of cooling time, total cycle time, volumetric shrinkage, and temperature variance using AMI software [9]. Although there are many studies on the analysis of CCC, the number of studies focusing on the design parameters of CCCs for different types of designs is very limited. Most of the designs have been applied based on the experience of the designers. To the author's knowledge. Mixtures of any kind as well as the agreement between the design parameters, the cross-section size and the respective experimental analyzes are rare. Nevertheless, some preliminary information could be obtained from the literature, which provides a basis for further research in this project. For example, a simple relationship between four parameters, for the design of CCC using additive manufacturing, can be found in Mayer [10]. Previous literature shows that the use of crosssections for channels other than circular could provide better cooling efficiency. Some research has been carried out to analyze cooling channels with variable spacing for mold tooling 
application [11]. For redesigning the existing model, which was originally built with straight channels, with CCC's, the authors conducted a study in which a comprehensive solution for conformal channel design was derived. Parameters such as duct diameter, pitch spacing and wall to duct spacing were considered by the authors. Only two original research articles on the topic of structural simulation of molds with conformal cooling channels have been found in the literature [12,13]. These two papers are about injection molding, and a structural analysis was done only to validate the geometries from a structural design point of view. However, no original research article that aims to determine the comparative effectiveness of a set of geometries for injection molds, in both stiffness and resistance, and according to several metrics, were found. The literature is significant regarding the numerical simulation, as it is shown. However, structural analysis of internally reinforced molds with cellular geometry were not found, with the aim of assessing the feasibility of their application in injection molding processes under working conditions. The main aim of this work was to evaluate the studied geometries with the objective to know which ones can be safely applied in injection molds. However, the metrics developed in this work could be applied to other geometries, as a tool to assess if other geometries could withstand the pressures that are characteristic of the injection molding process.

\section{Injection Molding}


Injection molding is a widely used advanced manufacturing technology for the low-cost and highly reliable production of engineered parts. The injection molding process involves several steps: (1) injection, (2) packaging, (3) cooling, and (4) ejection [14]. Injection molding is an important part of the plastics industry and consumes a large percentage of the total amount of plastics [15]. Plastic injection molding is a versatile process for producing various complex sizes and shapes of high-quality products from thermoplastic and thermoset materials by applying heat and pressure [16]. To obtain a high-quality plastic part, the design of the injection mold, especially the design of the mold core and cavity, is very important. It also plays an important role in the economic aspects of the business. Cooling channels must be used in the molds to ensure temperature control and cooling of the molded part. Traditionally, cooling channels were drilled straight using subtractive manufacturing methods. CCCs could be easily and economically fabricated using traditional methods. However, there are serious constraints on the geometry of CCC's that can limit the efficiency of the injection molding process. In fact, straight drilled channels are not able to induce optimal cooling because the shape of the cavity, in order to avoid any interference between the cavity and the channel, and the drilling process limit their design. In the latter case, only straight holes can be drilled. Fig. 1 shows the representation of cooling channels. 
a)

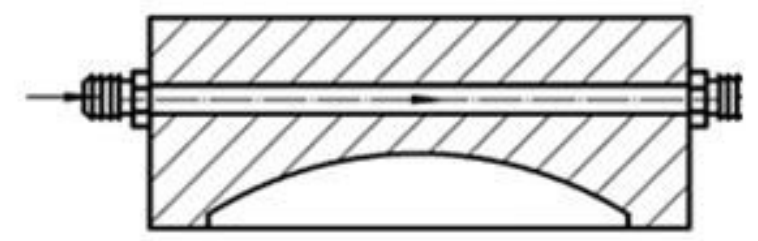

b)

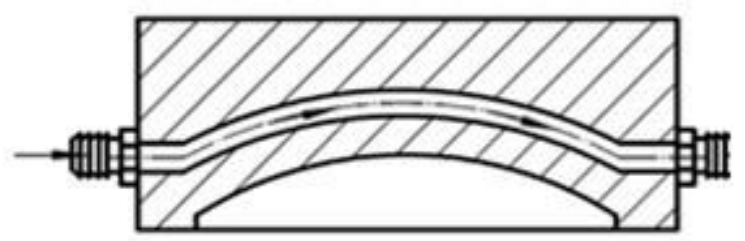

c)

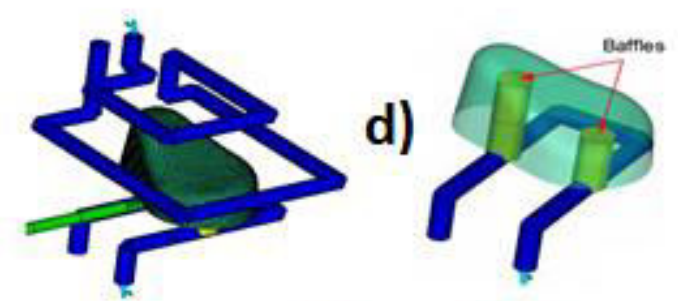

e)

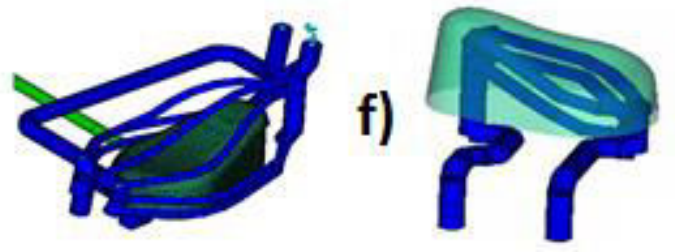

Fig. 1 (a) straight-drilled and (b) conformal [17]; Comparison of straight-drilled cooling channels and CC channels: straight-drilled cooling channels in cavity insert (c) and in core insert (d), and CC channels in cavity insert (e) and in core insert (f) (Adapted from [18], in [19].

Due to the inherent limitations, straight drilled circular channels are not able to provide efficient cooling and pose constraints for cooling channel design optimization due to the limitations in geometry.

\section{Theoretical fundaments: The Finite Element Method}

The fact that no analytical model is available to accurately determine the mechanical behavior of the geometries studied in this work, made the use of numerical methods, in this case, the FEM, 
a feasible and very useful option. As the results of this work were only obtained in the FEM software ANSYS Workbench, the next sub-sections present some of the relevant background for the understanding of the method.

\subsection{Solution procedure}

Modeling an engineering problem with finite elements requires the composition of elementary characteristic (stiffness) matrices and elementary vectors of the right-hand side (force), leading to the global system of equations:

$\mathbf{K} \mathbf{u}=\mathbf{F}$

where $\mathbf{K}$ is the set of element characteristic matrices, called the global matrix system, and $\mathbf{F}$ is the set of element vectors of the right-hand side, called the global vector of the right-hand side (force). The vector of node unknowns is represented by $\mathbf{u}$.

The global system matrix, K, can be obtained from the "extended" element coefficient matrices, $\mathbf{k}^{\text {(e) }}$, by reformulation in the form:

$$
K=\sum_{e=1}^{E} k^{(e)}
$$

where the divisor $E$ denotes the total number of elements. The "extended" characteristic element matrices have the same size as the global system matrix, but have rows and columns with zeros 
corresponding to the nodes not associated with the element (e). The size of the global system matrix is dictated by the highest number of the global nodes numbers.

Similarly, the global right-hand side vector, F, can be constructed from the "extended" element coefficient vectors, $\mathrm{f}^{(\mathrm{e})}$, by the sum shown in Eq. (3)

$$
F=\sum_{e=1}^{E} f^{(e)}
$$

The "extended" element vectors on the right-hand side have the same size as the global vector on the right-hand side, but contain rows of zeros corresponding to nodes not connected to element (e). The size of the global vector on the right-hand side is also determined by the highest number among the global numbers.

For the global system of equations to have a unique solution, the determinant of the global system matrix must be nonzero. However, an examination of the global system matrix reveals that one of its eigenvalues is zero, resulting in a zero determinant or singular matrix. Therefore, the solution is not unique. The eigenvector corresponding to the zero eigenvalue represents the translation mode, and the remaining non-zero eigenvalues represent all deformation modes.

For the specific values of and, the global system matrix becomes

$$
K=k^{(e)}\left[\begin{array}{cccc}
1 & -1 & 0 & 0 \\
-1 & 3 & -2 & 0 \\
0 & -2 & 3 & -1 \\
0 & 0 & -1 & 1
\end{array}\right]
$$


with its eigenvalues:

$\lambda_{1}=0, \lambda_{2}=2, \lambda_{3}=3-\sqrt{5}, \lambda_{4}=3+\sqrt{5}$

and

The corresponding eigenvectors are

$u^{(1)}=\left\{\begin{array}{l}1 \\ 1 \\ 1 \\ 1\end{array}\right\}, u^{(2)}=\left\{\begin{array}{c}1 \\ -1 \\ -1 \\ 1\end{array}\right\}, u^{(3)}=\left\{\begin{array}{c}-1 \\ 2-\sqrt{5} \\ -2+\sqrt{5} \\ 1\end{array}\right\}, u^{(4)}=\left\{\begin{array}{c}-1 \\ 2+\sqrt{5} \\ -2-\sqrt{5} \\ 1\end{array}\right\}$

Both of these eigenvectors represent a possible solution mode. In order for the global system of equations to have a unique solution, the global system matrix is made nonsingular by eliminating the zero eigenvalue. This is achieved by introducing a boundary condition to suppress the translational mode of the solution corresponding to the zero eigenvalue [20].

\subsection{Quadratic Triangular Element with six nodes}

The field variable can be approximated by a complete quadratic function within a triangular element of the form 
$\phi^{(e)}(x, y)=\alpha_{1}+\alpha_{2} x+\alpha_{3} y+\alpha_{4} x^{2}+\alpha_{5} x y+\alpha_{6} y^{2}$

or

$\phi^{(e)}(x, y)=g^{T} \alpha$

where the vectors $g$ and a are defined by

$g^{T}=\left\{\begin{array}{llllll}1 & \mathrm{x} & \mathrm{y} & \mathrm{x}^{2} & \mathrm{xy} & \mathrm{y}^{2}\end{array}\right\}$

And

$$
\alpha^{T}=\left\{\begin{array}{llllll}
\alpha_{1} & \alpha_{2} & \alpha_{3} & \alpha_{4} & \alpha_{5} & \alpha_{6}
\end{array}\right\}
$$

However, this representation requires a triangular element with six nodes, to determine its six unknowns @®coefficients :

At each node, the field variable is evaluated as.

$$
\left\{\begin{array}{l}
\phi 1 \\
\phi 2 \\
\phi 3 \\
\phi 4 \\
\phi 5 \\
\phi 6
\end{array}\right\}=\left[\begin{array}{llllll}
1 & x_{1} & y_{1} & x_{1}^{2} & x_{1} y_{1} & y_{1}^{2} \\
1 & x_{2} & y_{2} & x_{2}^{2} & x_{2} y_{2} & y_{2}^{2} \\
1 & x_{3} & y_{3} & x_{3}^{2} & x_{3} y_{3} & y_{3}^{2} \\
1 & x_{4} & y_{4} & x_{4}^{2} & x_{4} y_{4} & y_{4}^{2} \\
1 & x_{5} & y_{5} & x_{5}^{2} & x_{5} y_{5} & y_{5}^{2} \\
1 & x_{6} & y_{6} & x_{6}^{2} & x_{6} y_{6} & y_{6}^{2}
\end{array}\right]\left\{\begin{array}{l}
\alpha_{1} \\
\alpha_{2} \\
\alpha_{3} \\
\alpha_{4} \\
\alpha_{5} \\
\alpha_{6}
\end{array}\right\} \text { or } \varphi=\mathrm{A} \alpha
$$


The solution for the generalized coordinates in terms of nodal coordinates and nodal values of the field variables yields

$\alpha=\mathrm{A}^{-1} \varphi$

Substituting the generalized coordinates into Eq. (1 )or ( 2) yields

$\phi^{(e)}(x, y)=g^{T} A^{-1} \varphi$

but can also be expressed within the element by using its nodal values $\mathrm{r} / \mathrm{J}$; as

$\phi^{(e)}(x, y)=\sum_{i=6}^{6} N_{i}(x, y) \phi_{i}$ or $\phi^{(e)}(x, y)=N^{T} \varphi$

where $\mathrm{N}$ is the vector of shape functions, $\mathrm{N} ;(\mathrm{i}=1.6)$.

\section{Procedure}




\subsection{Material properties}

The material used in the simulations was steel P20. It is assumed that the material behaves as orthotropic, according to ref. $[21,22]$ The properties of the steel used are shown in Table 1 .

Table 1 - properties of the steel used [21,22]

\begin{tabular}{|l|l|l|}
\hline Property & Value & Units \\
\hline Ey & 180 & $\mathrm{GPa}$ \\
\hline Ex=Ez & 185 & $\mathrm{Gpa}$ \\
\hline$v_{\mathrm{x}}=v_{\mathrm{y}=v_{\mathrm{z}}}$ & 0.29 & {$[-]$} \\
\hline $\mathrm{G}_{\mathrm{xz}}$ & 69.8 & $\mathrm{GPa}$ \\
\hline $\mathrm{G}_{\mathrm{yz}}$ & 71.7 & $\mathrm{GPa}$ \\
\hline $\mathrm{G}_{\mathrm{xy}}$ & 71.7 & $\mathrm{GPa}$ \\
\hline$\rho$ & 7900 & $\mathrm{~kg} / \mathrm{m}^{\wedge} 3$ \\
\hline
\end{tabular}

The values of Gxy, Gyz, and Gxz are required in ANSYS Workbench 2020 R2 and were not in [20,21]. Therefore, they were determined from Ez, Ex and Ey. 


\section{2 Numerical models}

The mesh used in finite element models is illustrated in Fig. 2

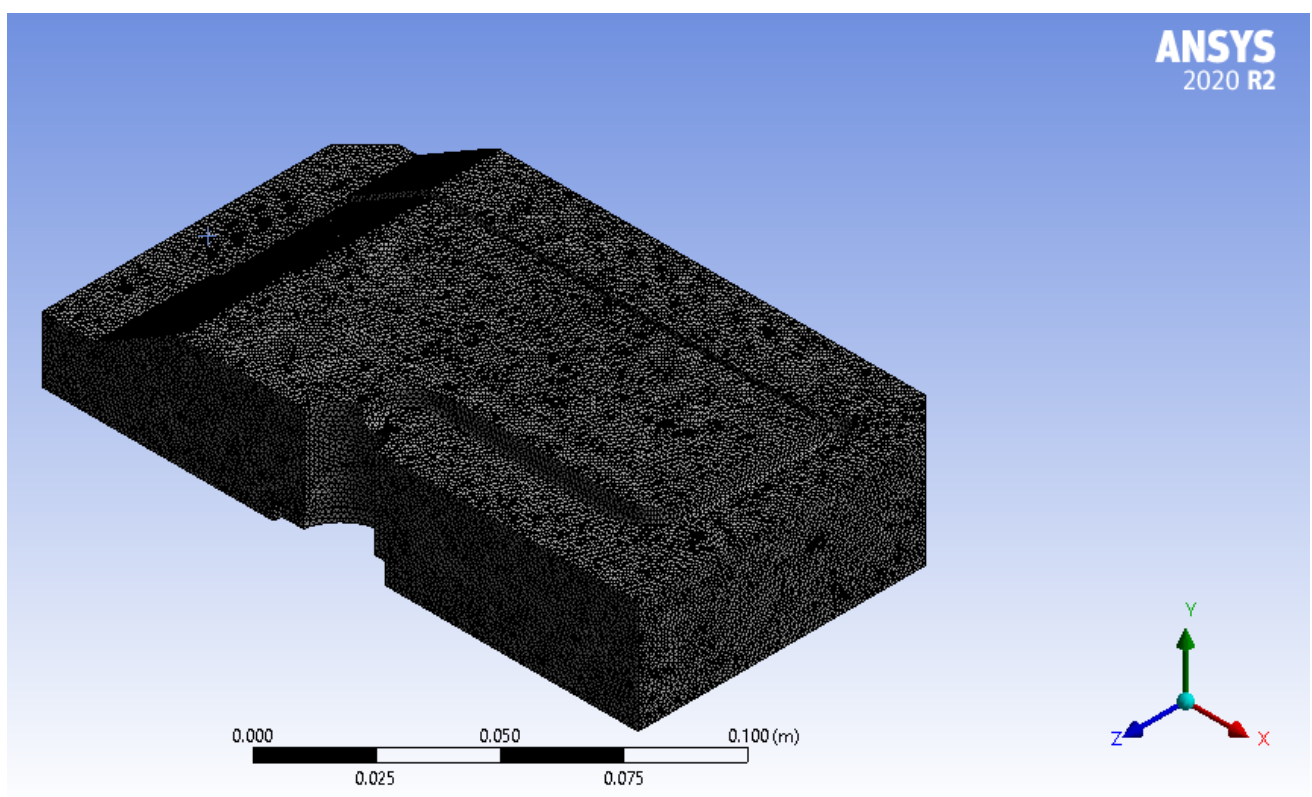

Fig. 2- Mesh used in ANSYS Workbench 2020 R2 software

The mesh parameters used are in Table 2:

Table 2- Mesh parameters used in the simulations in ANSYS Workbench 2020 R2

\begin{tabular}{|l|l|}
\hline Mesh parameters & Type/value \\
\hline Mesh type & Tetrangular free \\
\hline Mean size & $1.25 \mathrm{~mm}$ \\
\hline
\end{tabular}


The analyzed geometries were built in the Computer-Aided Design (CAD) software Solidworks 2020. The geometries were exported in a neutral file format and imported into ANSYS

Workbench. The analyzed CAD geometries are shown in Fig. 3-9.

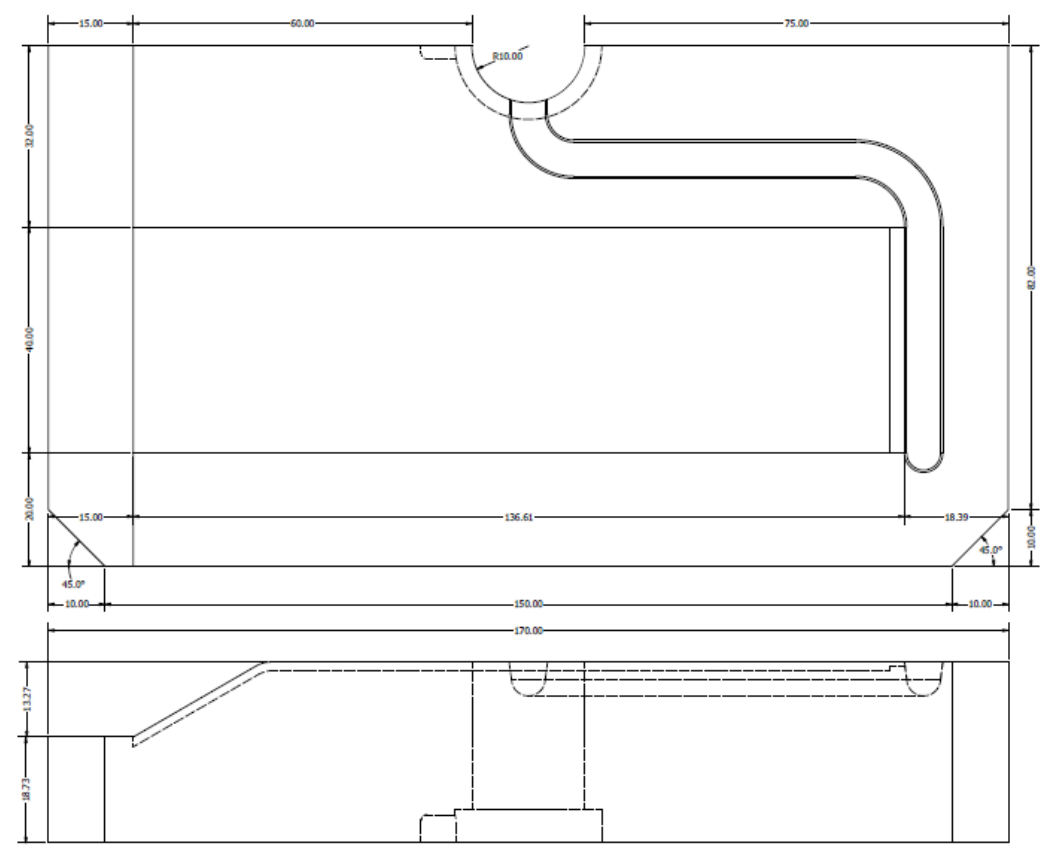

Fig. 3- Geometry "Bulk"

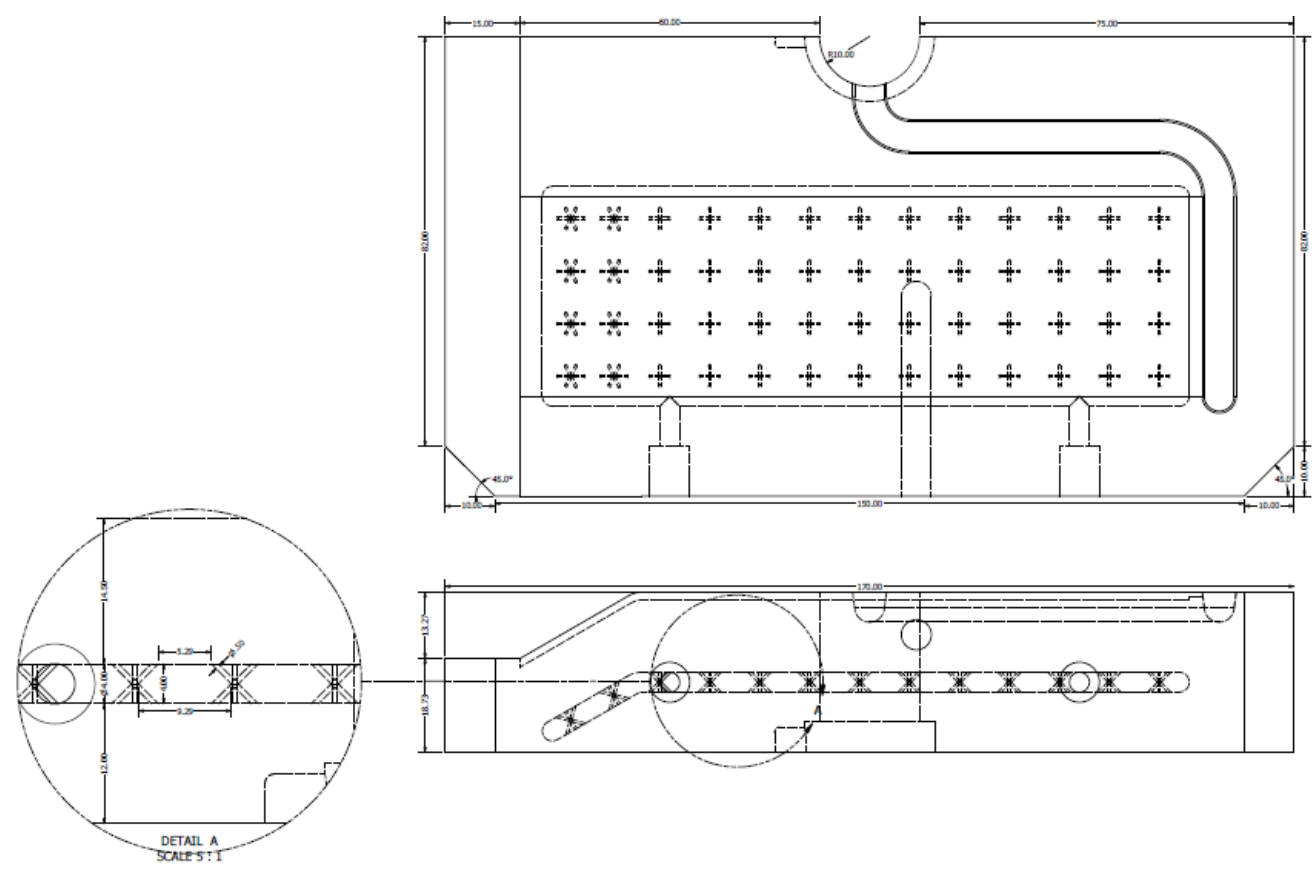


Fig. 4- Geometry "New 1"

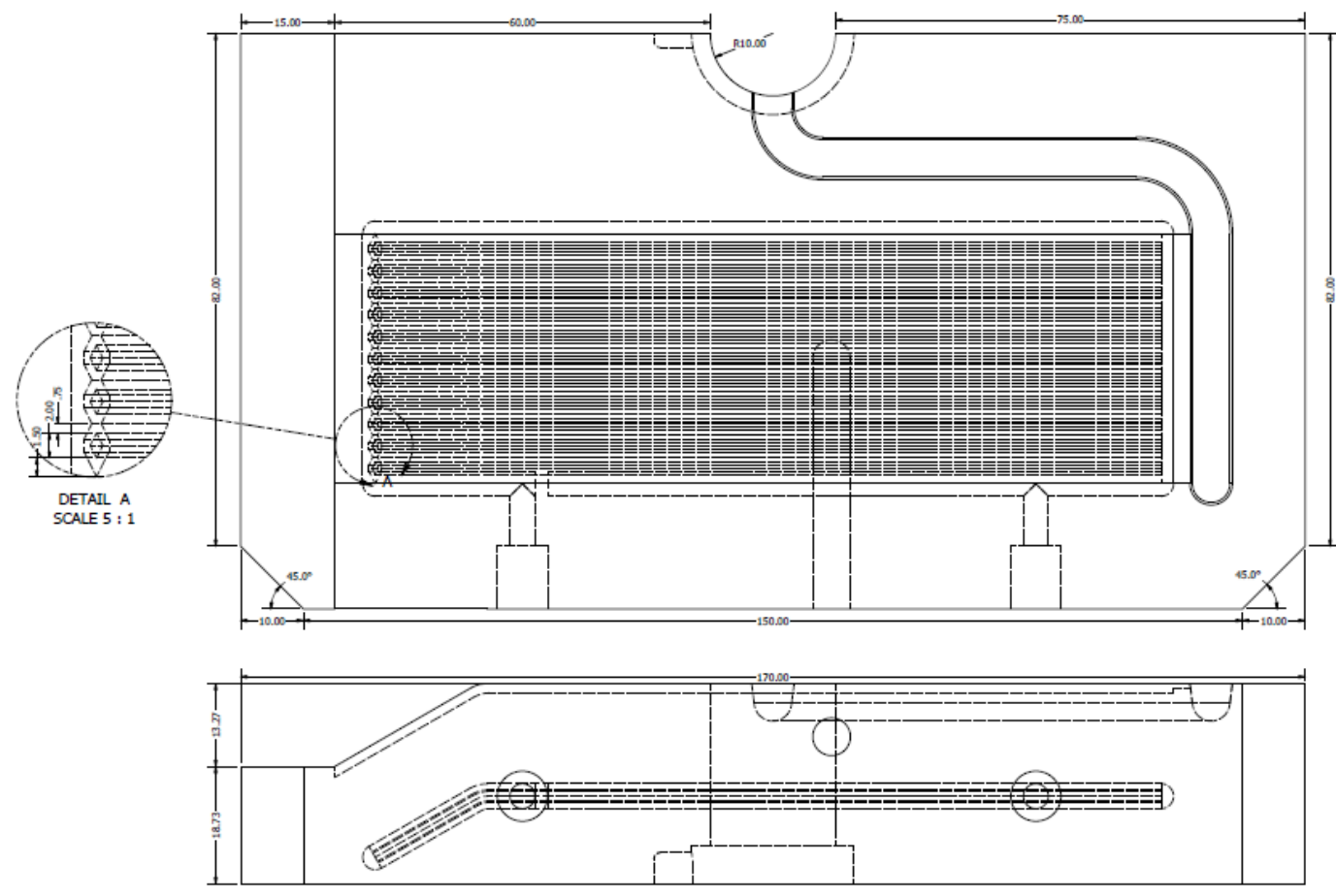

Fig. 5- Geometry "New 2"
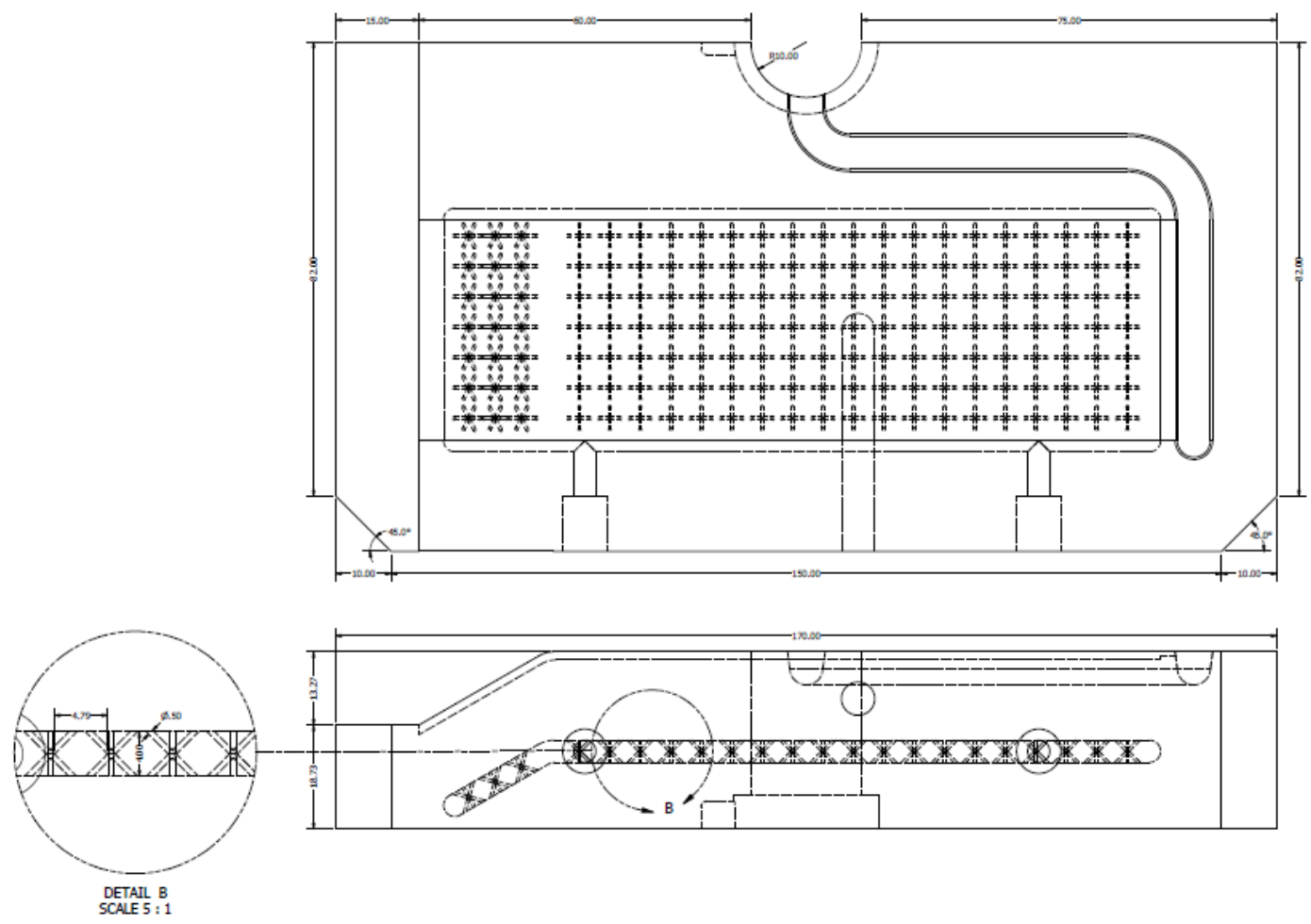
Fig. 6 Geometry "New 3"

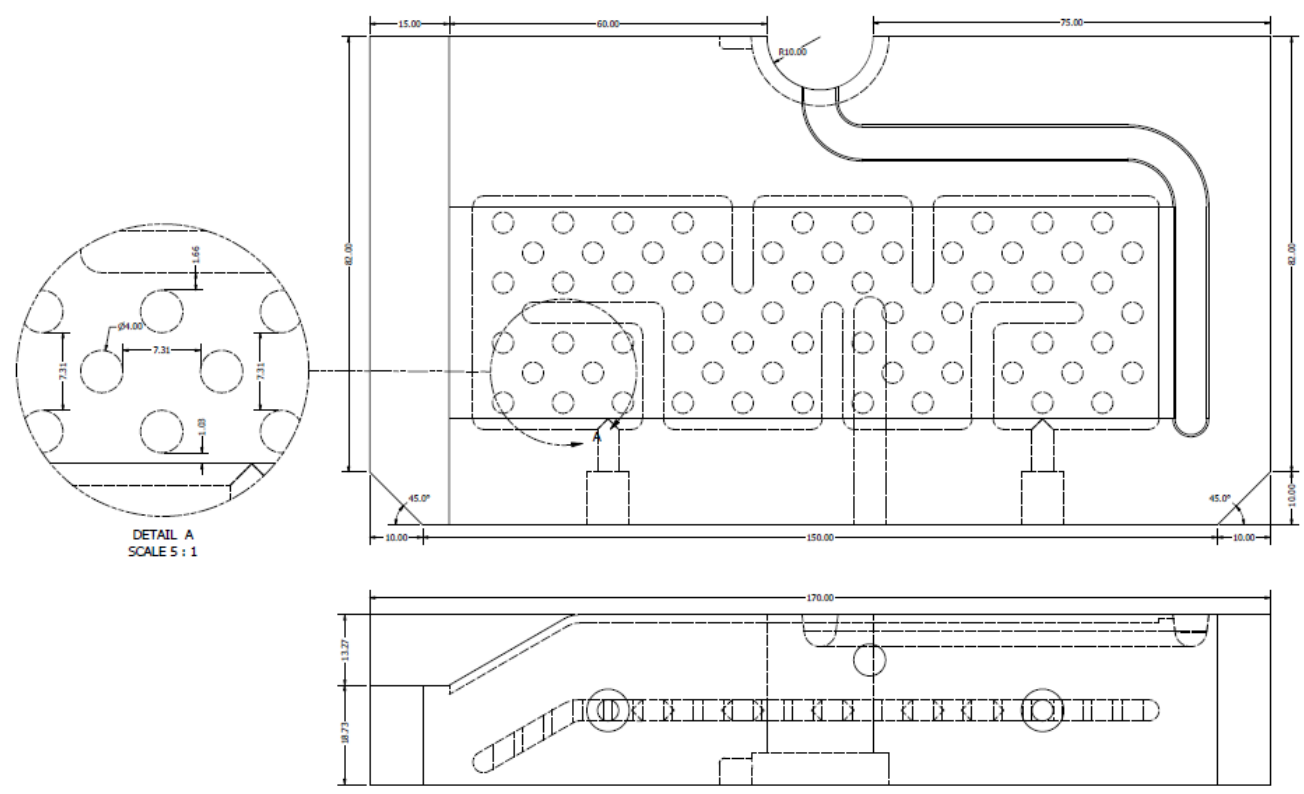

Fig. 7- Geometry "New 4"

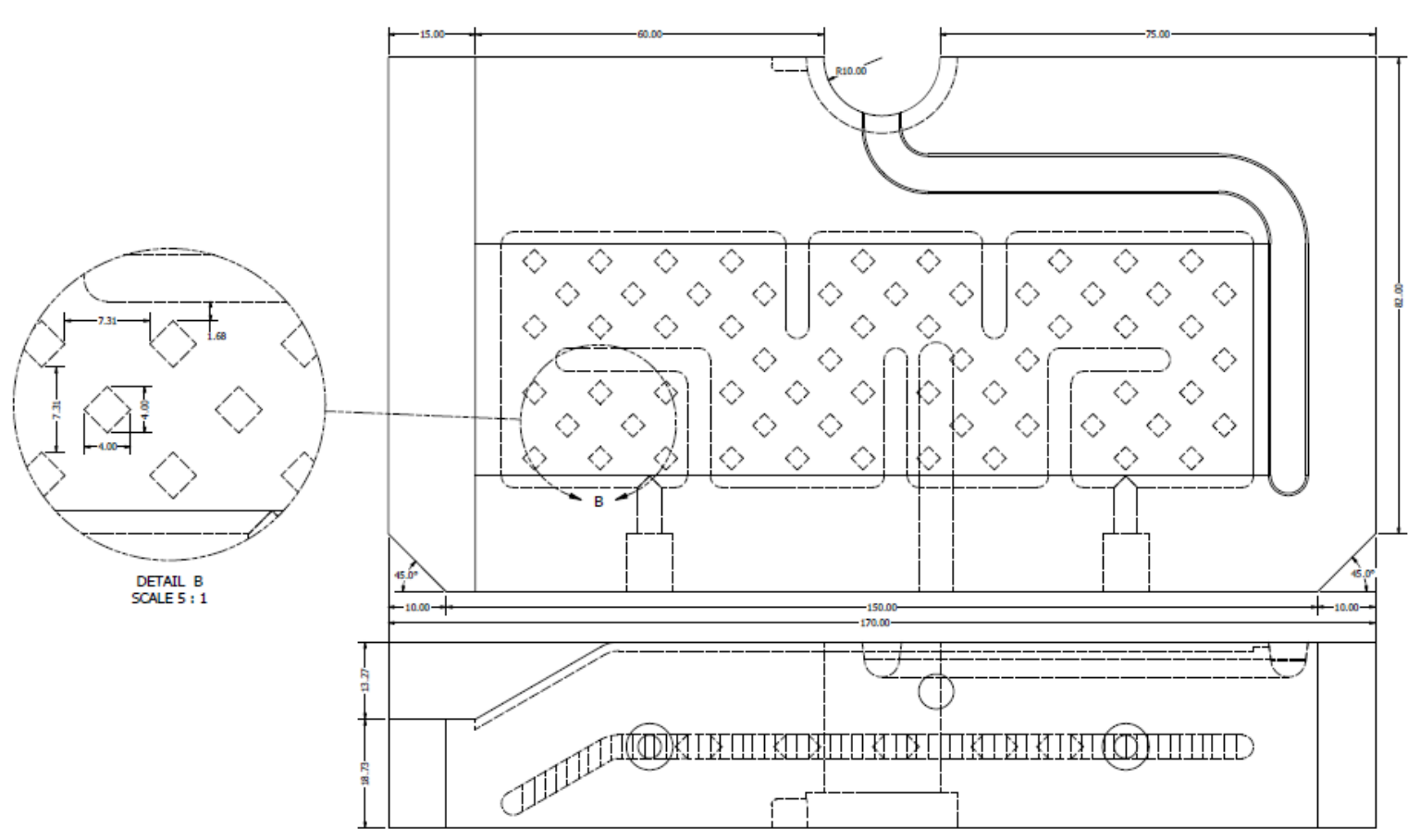

Fig. 8- Geometry “New 5" 


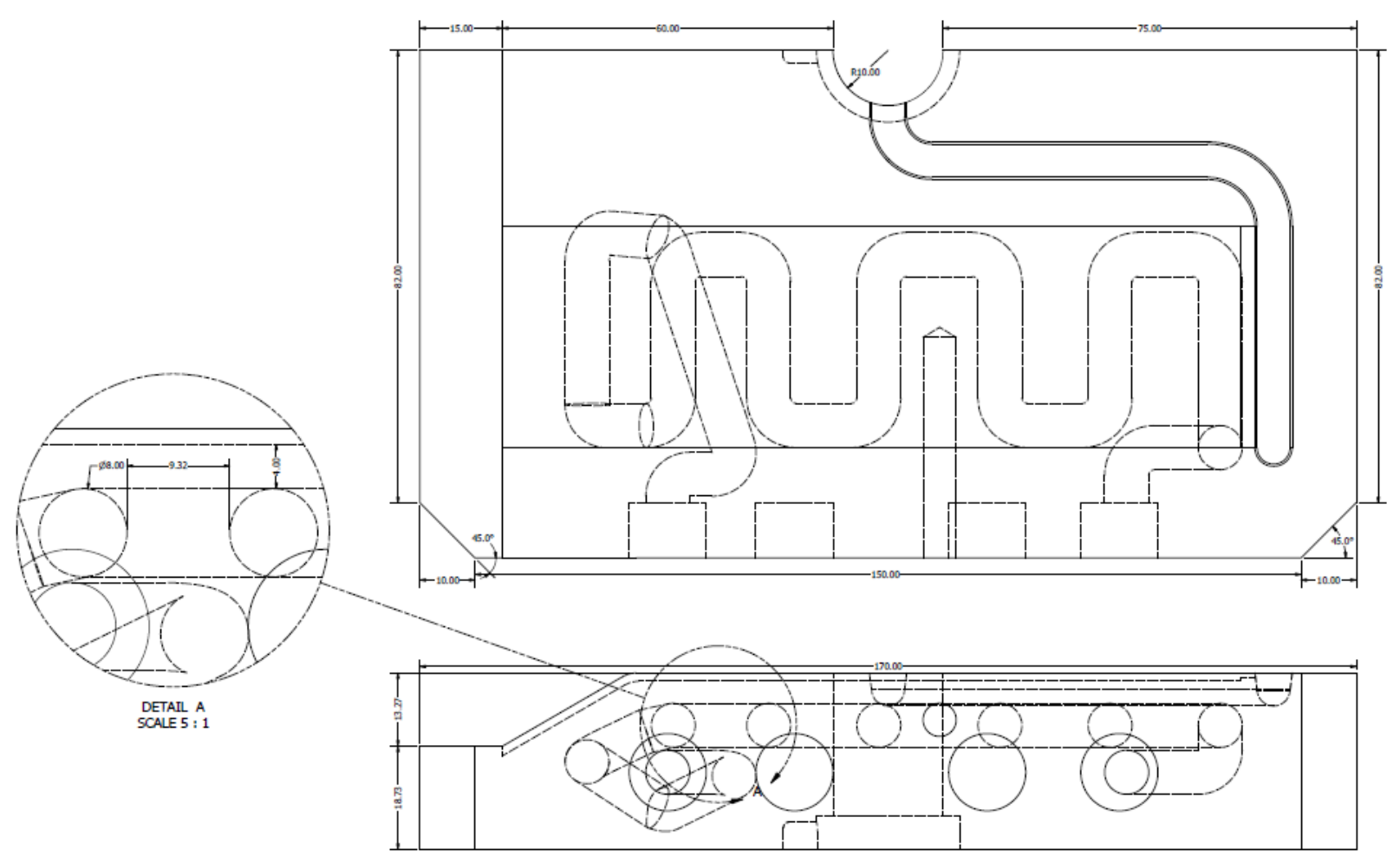

Fig. 9- Geometry "New 6"

The geometries shown in Fig. 3-9 were designed in CAD software, for assessment of their feasibility in injection molds, at a later stage.

\subsection{Conditions}

In order to simulate the pressure that the injected part is subjected to in the injection molding process, the part was subjected to a distributed load (pressure) in all the top faces, including the feeding channels (Fig. 10). 


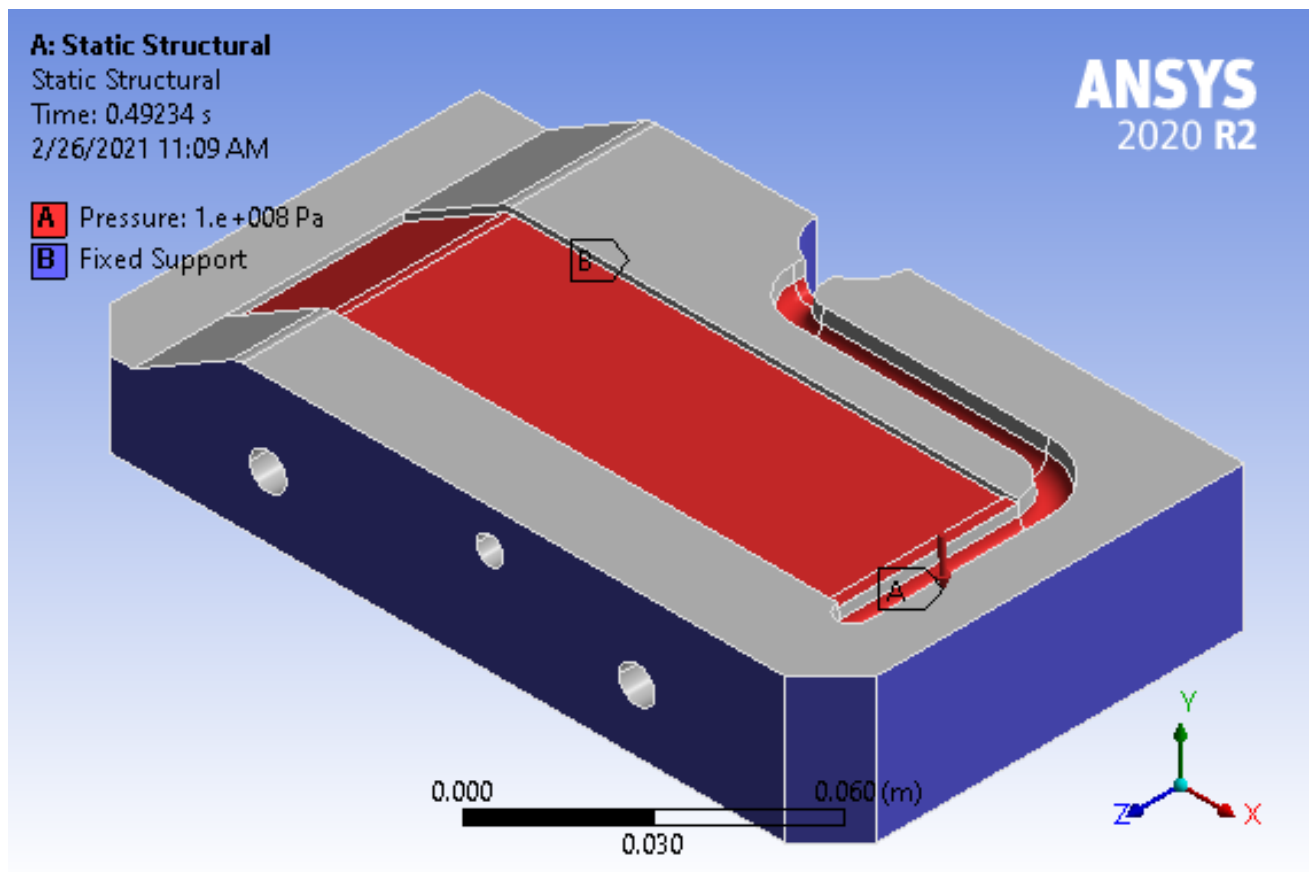

Fig. 10- Load applied. The pressure intensity caused by the distributed load is $100 \mathrm{MPa}$.

A pressure of $100 \mathrm{MPa}$ was applied. This pressure is within the range of the typical injection pressures, which are between $14 \mathrm{MPa}$ e $310 \mathrm{MPa}$ [23]. The part was supported in the way that is the closest to the real situation of a mold in the injection molding machine. The constraints applied to the numerical models are shown in Fig. 11, respectively.
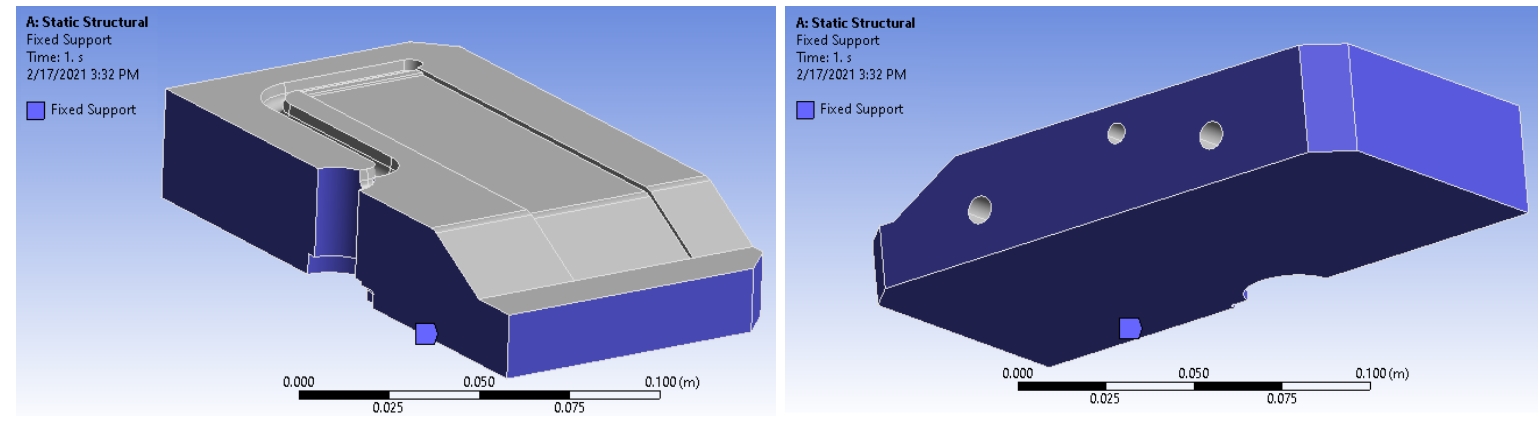
Fig. 11- DOF constraints applied to all the FEM models.

All the degrees of freedom (DOF) were constrained, so the constrained faces do not allow any translational or rotational motion.

\subsection{Evaluation of the mechanical behavior}

The evaluation of the mechanical behavior of the studied geometries was performed by means of several metrics. Of particular importance is the assessment of the combined relationship of the stiffness, resistance and mass. Due to the loading mode, the deflection according to the y axis is the most relevant metric in terms of stiffness. In terms of resistance, the normal stresses along the longitudinal direction (bending stresses) are relevant. However, because the loading is not applied in an entirely free surface and the geometry has some complexity, there might be non-negligible stresses according to other directions/axis. For that reason, Huber-Mises Yield Criterion was used for the determination of the resistance behavior. The relationship between the deflection and the mass can be expressed, in general terms by:

$\delta y_{E f f}=f(\delta y, m)$

Similarly, the relationship between Huber-Mises Stresses and the mass can be expressed by:

$\sigma_{V M_{E f f}}=f\left(\sigma_{V M}, m\right)$ 
As the aim is to both minimize the deflection and the mass, the effective behavior in terms of stiffness can be calculated as:

$\delta y_{E f f}=\delta y^{*} m$

The effective resistance behavior also can be determined in the same way:

$\sigma_{V M_{E f f}}=\sigma_{V M} * m$

An objective can be defined in terms of stiffness, considering the ratio between the effective stiffness of the model I, which represents the ID of each of the new geometries:

$\operatorname{obj}_{\delta_{\mathrm{y}}}=\frac{\left[\delta_{\mathrm{y}_{E f f}}\right]_{i}}{\left[\delta_{\mathrm{y}_{E f f}}\right]_{r e f}}=\frac{\left[\delta_{\mathrm{y}} \cdot \mathrm{m}\right]_{\mathrm{i}}}{\left[\delta_{\mathrm{y}} \cdot \mathrm{m}\right]_{\mathrm{ref}}}$

An objective regarding the resistance behavior can be defined in the same manner:

$\mathrm{obj}_{\sigma \mathrm{VM}}=\frac{\sigma_{\mathrm{VM}_{\mathrm{Eff}}}}{\sigma_{\mathrm{VM}_{\mathrm{Eff}}}}=\frac{\left[\sigma_{\mathrm{VM}} \cdot \mathrm{m}\right]_{\mathrm{i}}}{\left[\sigma_{\mathrm{VM}} \cdot \mathrm{m}\right]_{\mathrm{ref}}}$

If one combines Eqs. (19) and (20), one gets: 
$\mathrm{obj}=\mathrm{w}_{1} \mathrm{obj}_{\delta_{\mathrm{y}}}+\mathrm{w}_{2} \mathrm{obj}_{\sigma v m}=\mathrm{w}_{1} \frac{\left[\delta_{\mathrm{y}} \cdot \mathrm{m}\right]_{\mathrm{i}}}{\left[\delta_{\mathrm{y}} \cdot \mathrm{m}\right]_{\mathrm{ref}}}+\mathrm{w}_{2} \frac{\left[\sigma_{\mathrm{vM}} \cdot \mathrm{m}\right]_{\mathrm{i}}}{\left[\sigma_{\mathrm{VM}} \cdot \mathrm{m}\right]_{\mathrm{ref}}}$

To assess the combined influences of deflections and Huber-Mises Stresses, the respective weights w1 and w2 must be defined. By default, w1=w2=0.5

\section{Results and discussion}

\subsection{Overall results}

Contours were obtained in ANSYS Workbench, as to assess the distribution of stresses and displacements. The aim of mechanical design and Computer Aided Engineering (CAE) engineers should be, in this case, to reinforce the part in the highest stresses and/or displacements, as to reduce critical stresses. Alternately, topology optimization fundaments can also be used, either automatically (using software) or manually, by reducing material on the points of lowest stresses. In the cases of the present paper, the contours may help redesign the parts, as to obtain lowest stresses and displacements. Fig. 12 shows graphic results, in terms of equivalent stresses, according to the Huber-Mises criterion, for the Bulk model. Fig. 12 (a) shows result values. Fig. 12 (b) is an enlargement of Fig. 12 (a). 


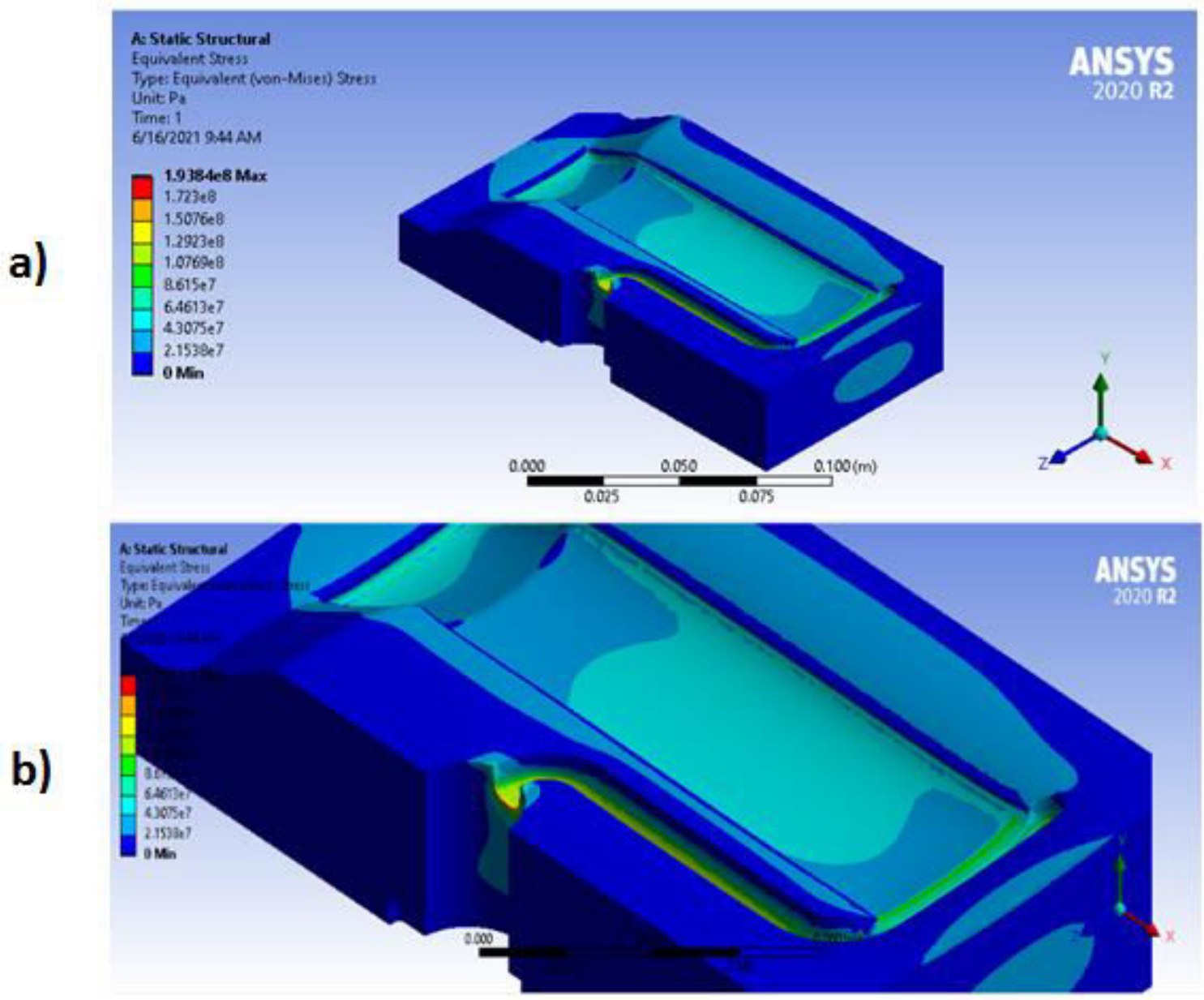

Fig. 12- Contours of strength results

The contours of Fig. 12 show highest Huber-Mises stresses close to the center of the areas of load application. While the contour might not present clear gradients of results, it is important to note that this is an equivalent stress, which is calculated according to the principal stresses. The relationships between the principal stresses might originate results, whose contours are non-trivial, such as in this case. Fig. 13 shows the graphical results in terms of displacement in 
the direction of the y axis, for the Bulk model. (see coordinate system in Fig. 13 (a). Fig. 13 (a) shows result values Fig. 13 (b) is an enlargement of Fig. 13 (a).

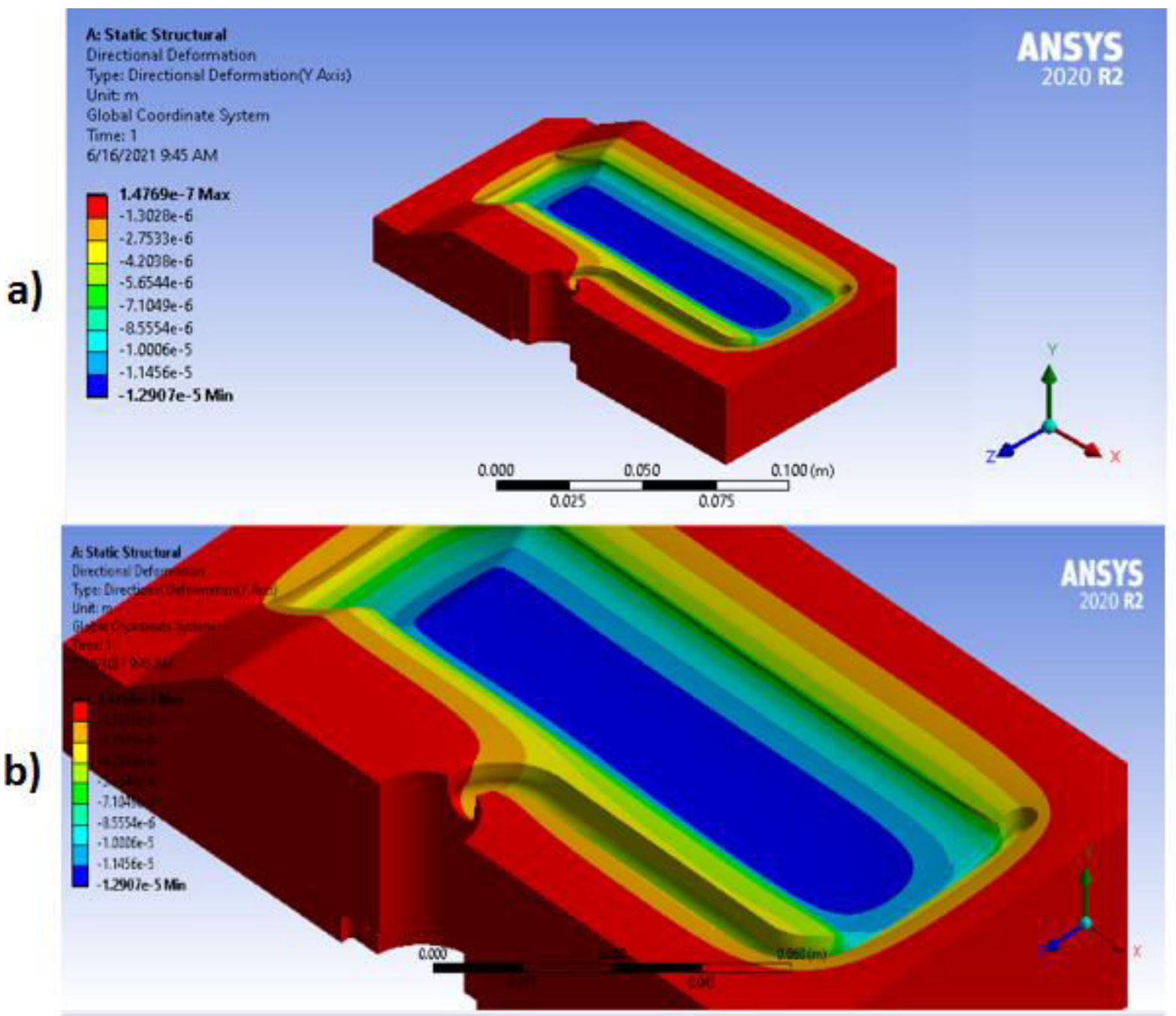

Fig. 13- Contours of stiffness results

The contour of Fig. 13 shows high deflections, in the vertical direction, in the place of load application, which is expected. There is a deflection gradient, caused by the distance to the areas of load application. 
A surface, in the xy plane, defined in the middle y coordinate of the part, was defined in ANSYS

Workbench. The results are shown in Fig. 14 (Strength) and Fig. 15 (Stiffness)

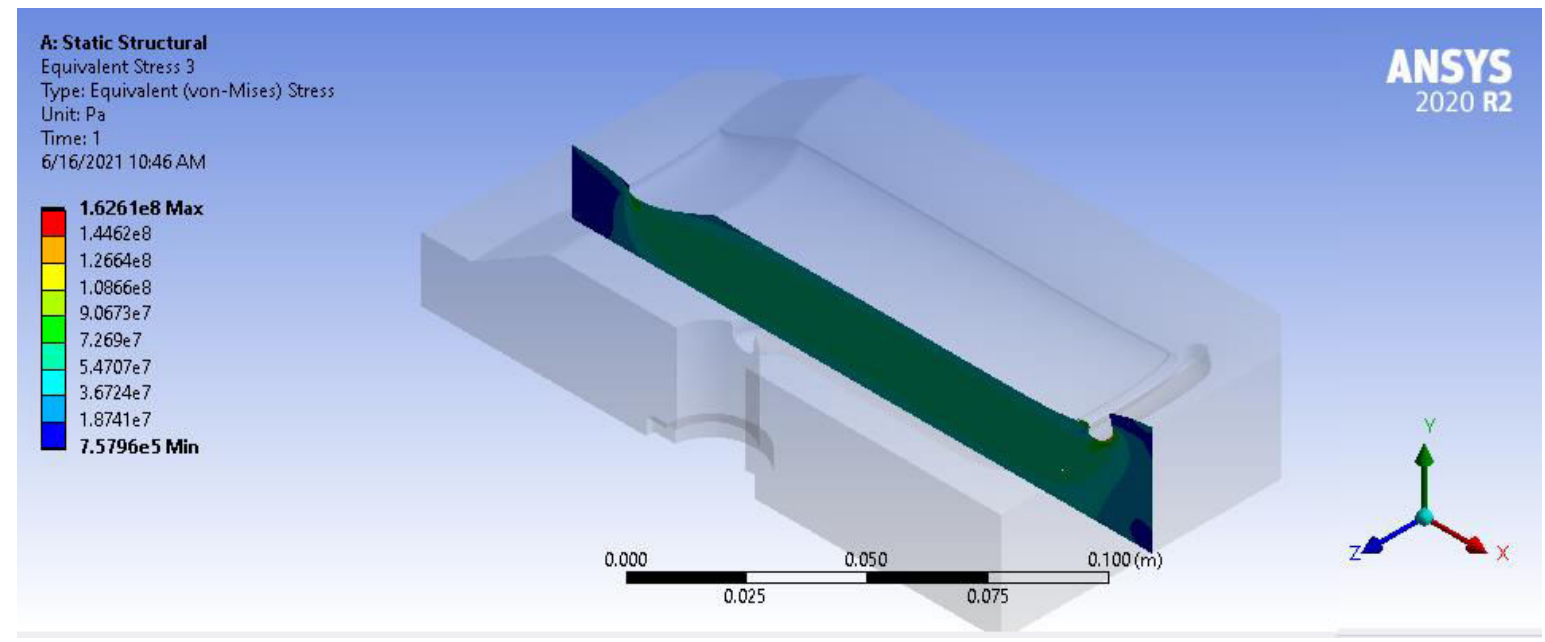

Fig. 14- Contours of strength results, midplane

One can see that the results on the surface are low enough to ensure structural safety. The bending stresses, for this loading mode and DOF constraints, occur predominantly in the surface defined.

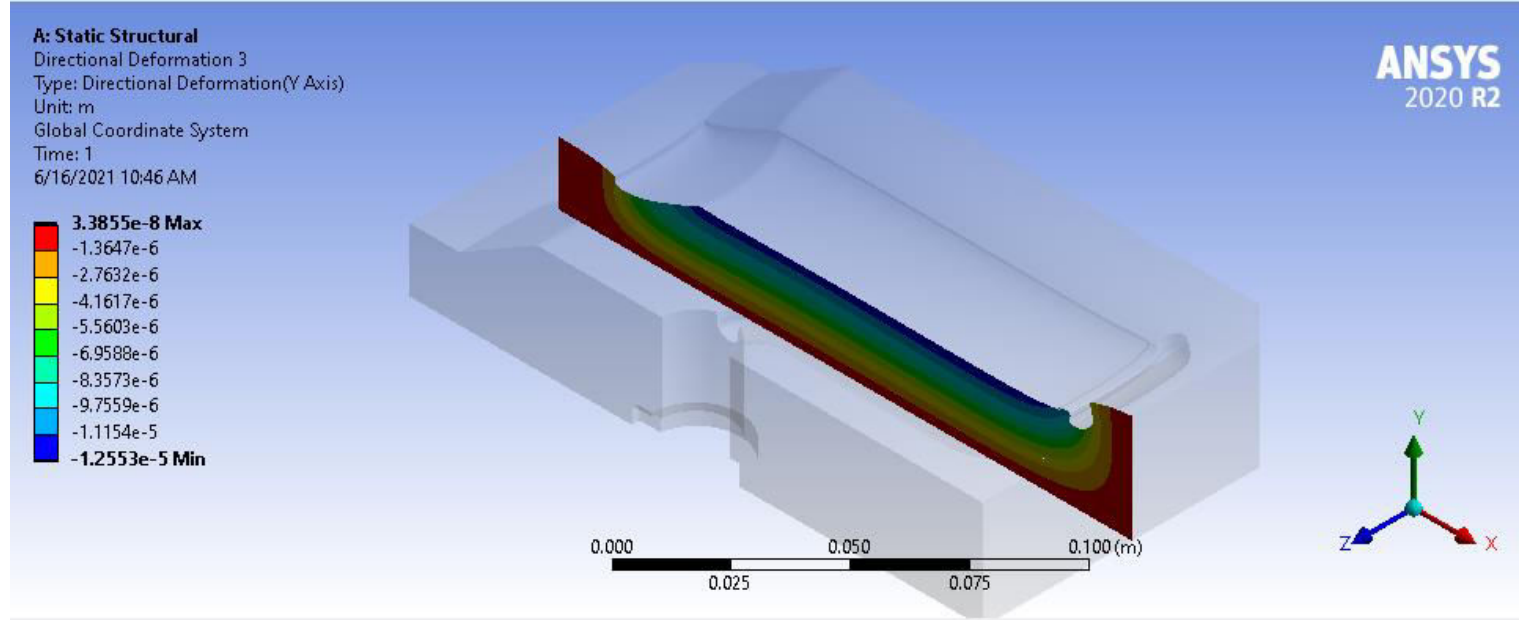


Fig. 15- Contours of stiffness results, midplane

The stiffness results shown in Fig. 15 show us that the top surface experience highest deflections, which is expected due to the distribuited load being applied at the top face, as well as due to the higher distance to the constrained areas. The gradient of the deflections shown in Fig. 15 is also very related to those two factors. The Huber-Mises stresses are shown in Fig.16.

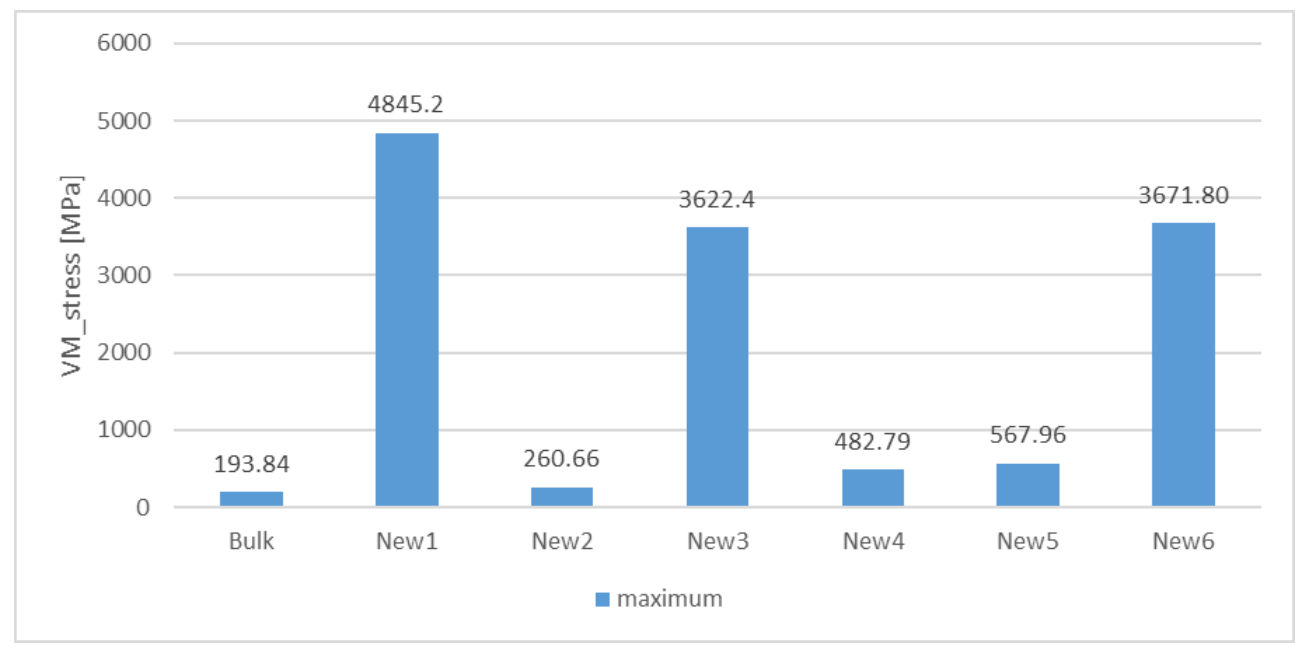

Fig. 16 -Huber-Mises Stresses for all the studied geometries

Fig. 17 shows the same results, but in a different scale in the vertical axis and with horizontal bold lines at 300, 500, 700 and $900 \mathrm{MPa}$, which is the typical range of Yield Strenghts of highstrenght steels. 


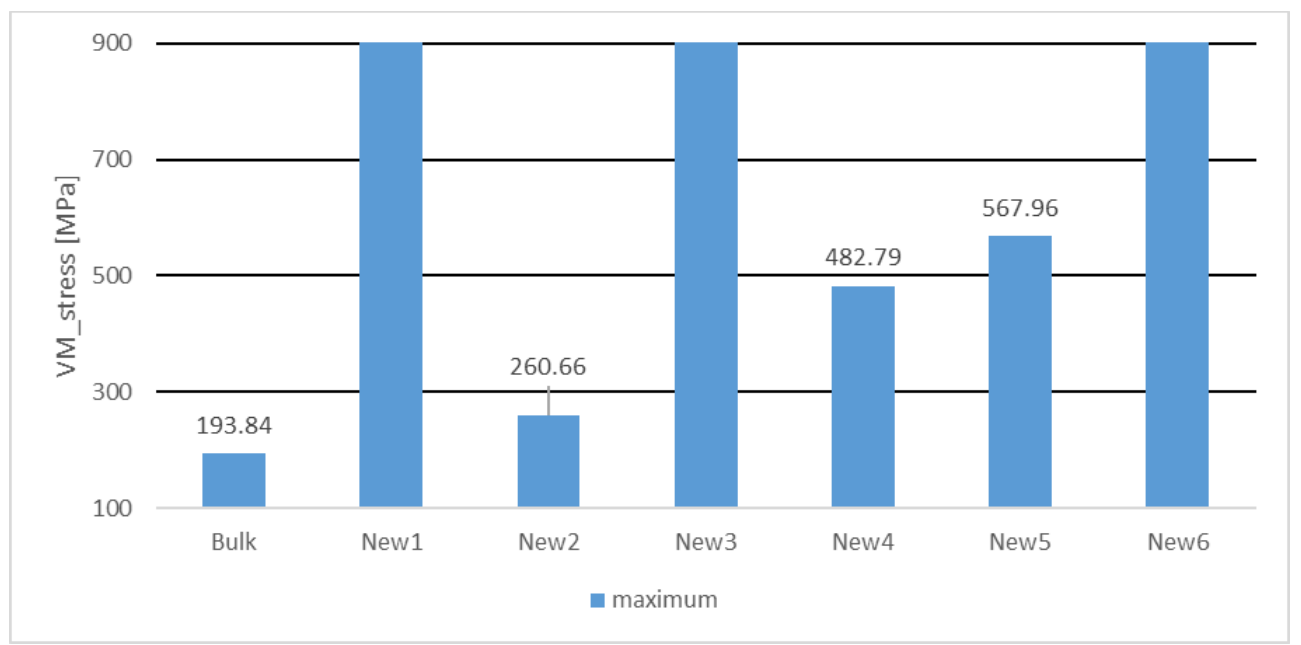

Fig. 17- Huber-Mises Stresses for all the studied geometries, zoom of Fig. 9, comparing the results with typical yield strengths of steels, range 300-900 MPa.

From Fig. 17, one can conclude that the geometries New1 and New2 are not feasible as they are, as no steel can withstand such levels of stress. At $700 \mathrm{MPa}$ of Yield strength, the Bulk, New2, New4 and New5 comply with the structural requirements. At $500 \mathrm{MPa}$, the geometries Bulk, New2 and New4 pass the structural evaluation. At the yield strength of $300 \mathrm{MPa}$, only the Bulk and the geometry New2 show maximum Huber-Mises strength below Yield. The vertical displacements were also analyzed. In fact, the structural reliability also relies on displacements, as warpage is a factor that should always be avoided as much as possible. Fig. 18 shows the maximum y displacements for all the geometries. 


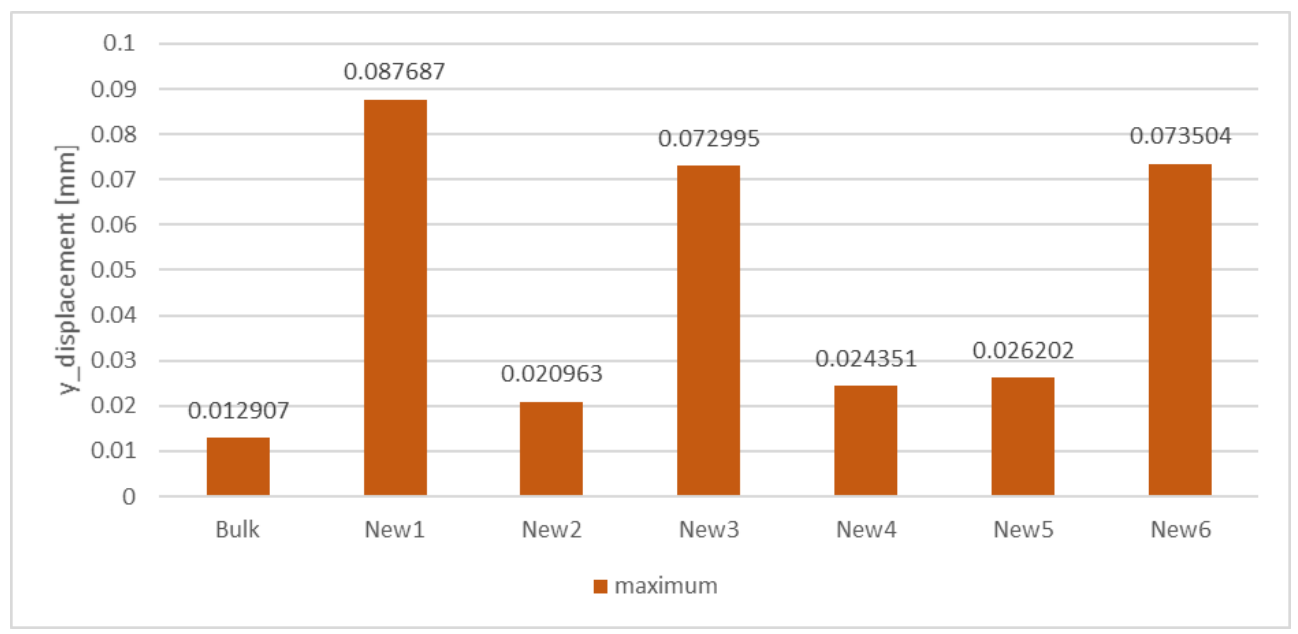

Fig. 18- Y displacement for all the studied geometries

Comparing the results of fig. 18 with those of Fig. 16, one can see that there are differences in the results. If one compares the results of all models in terms of deflections and Huber-Mises stresses, one can see that, although the results have some similarities, the proportions of the bars show some divergences. This is due to the fact that Huber-Mises yield criterion uses principal stresses, while deflections studied herein only consider one direction.

\subsection{Comparison between geometries/models}

Although the results shown in Figs. 9-11 are certainly relevant, the comparison between the geometries is also important. It allows the selection of the best geometry for an application, as well as the quantification of improvement or worsening between different geometries. All the geometries are compared to the Bulk one, as the Bulk is the one that behaves best, without accounting other factors, such as the mass. 
Equations (22) and (23) were the equations that were used to build the results of Figs. 19 and 20, by means of the results of Figs. 16/17 and 18.

$\sigma_{\text {rel }}=\left(\sigma_{x}-\sigma_{b u l k}\right) / \sigma_{b u l k} * 100$

$\delta_{\text {rel }}=\left(\delta y_{x}-\delta_{b u l k}\right) / \delta_{b u l k} * 100$

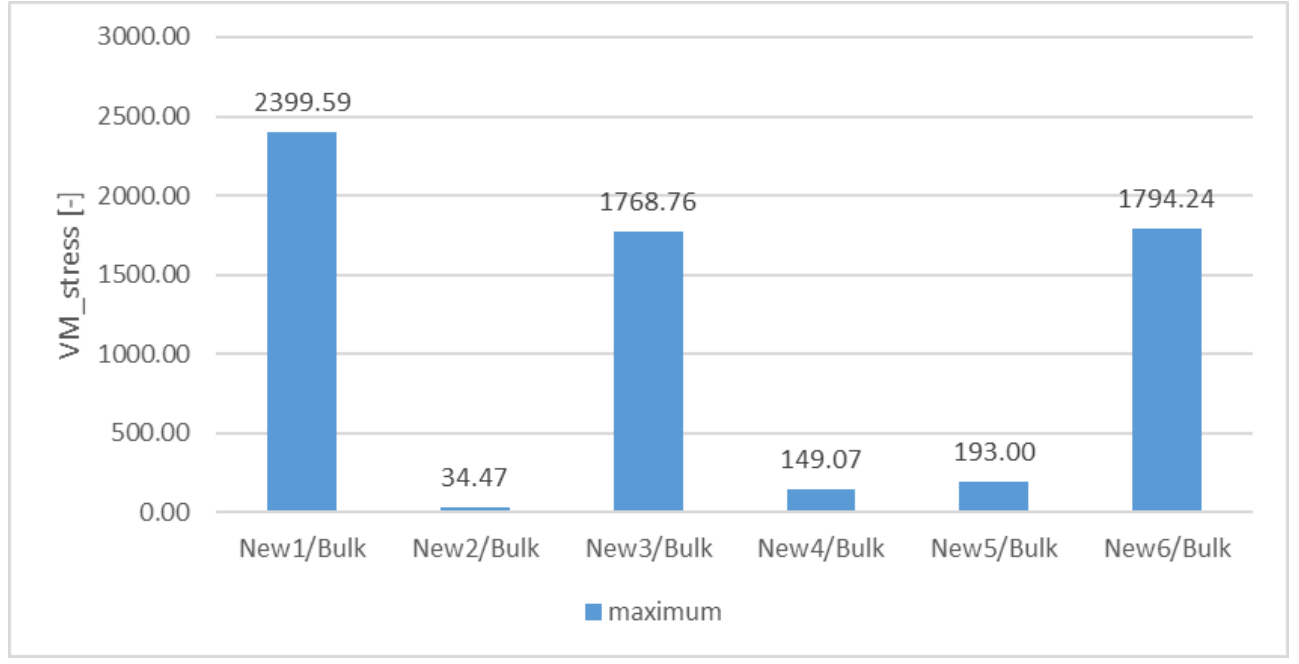

Fig. 19-Efficiency results in terms of resistance

The results of Fig. 19 quantity how higher are the Huber-Mises Stresses of each of the new geometries in comparison with the bulk one. The best result was obtained for the geometry New2, with only an increase of $34 \%$ in comparison with the bulk geometry. The geometry New1 
shows the worst results, with an increase of $2399.59 \%$ in comparison with the bulk one. Fig. 20 shows efficient results, considering the stiffness.

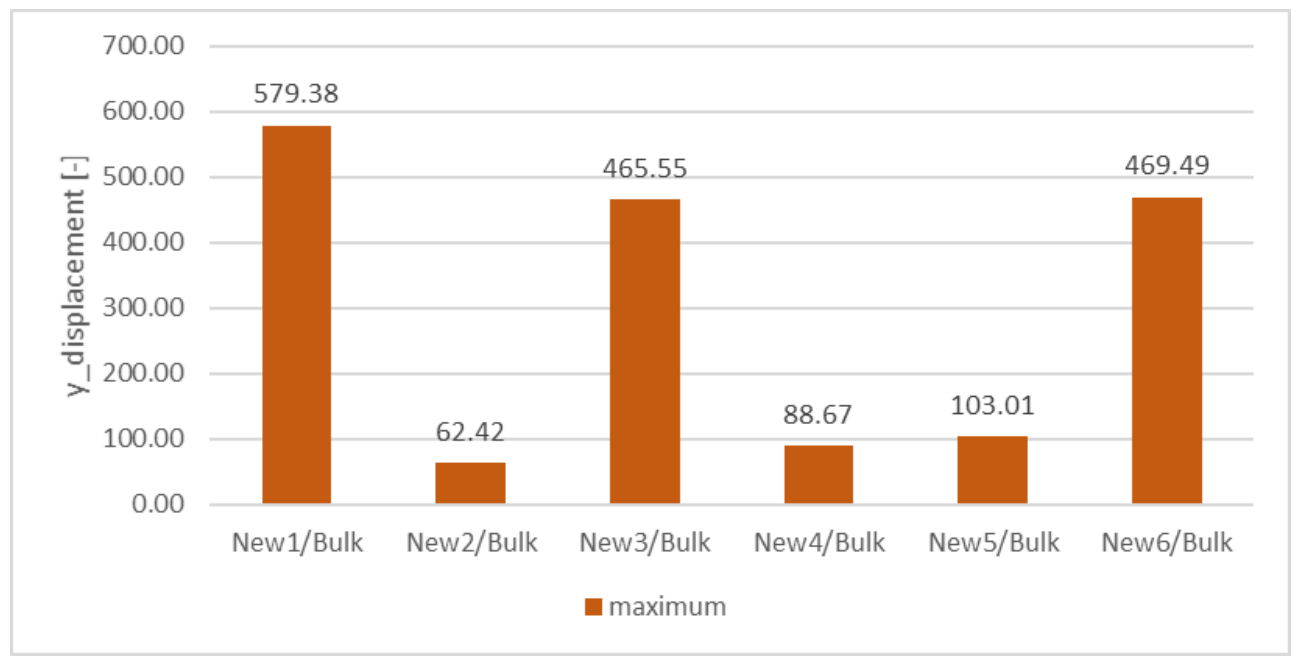

Fig. 20-Efficiency results in terms of stiffness

The results of Fig. 20 quantity how the y displacements of each of the new geometries in compare with the bulk geometry, similarly to what was shown in Fig. 12 for Huber-Mises Stresses. The best result was obtained for the geometry New2, with only an increase of $62 \%$ in comparison with the bulk geometry. The geometry New1 shows the worst results, with an increase of $579.38 \%$ in comparison with the bulk one. It is important to note that the bulk geometry is, by nature, structurally stiffer. However, the results considering the mass might yield much more interesting conclusions about the relative effectiveness of all solutions.

\subsection{Mass Results}


The mass is important in the case of injection molds, because a reduction of the mass allows to shorten the injection cycle, increasing therefore the production rate of plastic part. Although the ejection stage only represents a small fraction of the injection molding cycle, improvements in the number of manufactured parts can be significant over a long period of time. If one multiplies Huber-Mises stresses or deflection by the mass, one gets the combined influence of mass on the stresses and on the deflections, respectively. The results are shown in Figs. 21 and 22. They were obtained from Eqs. (17) and 18).

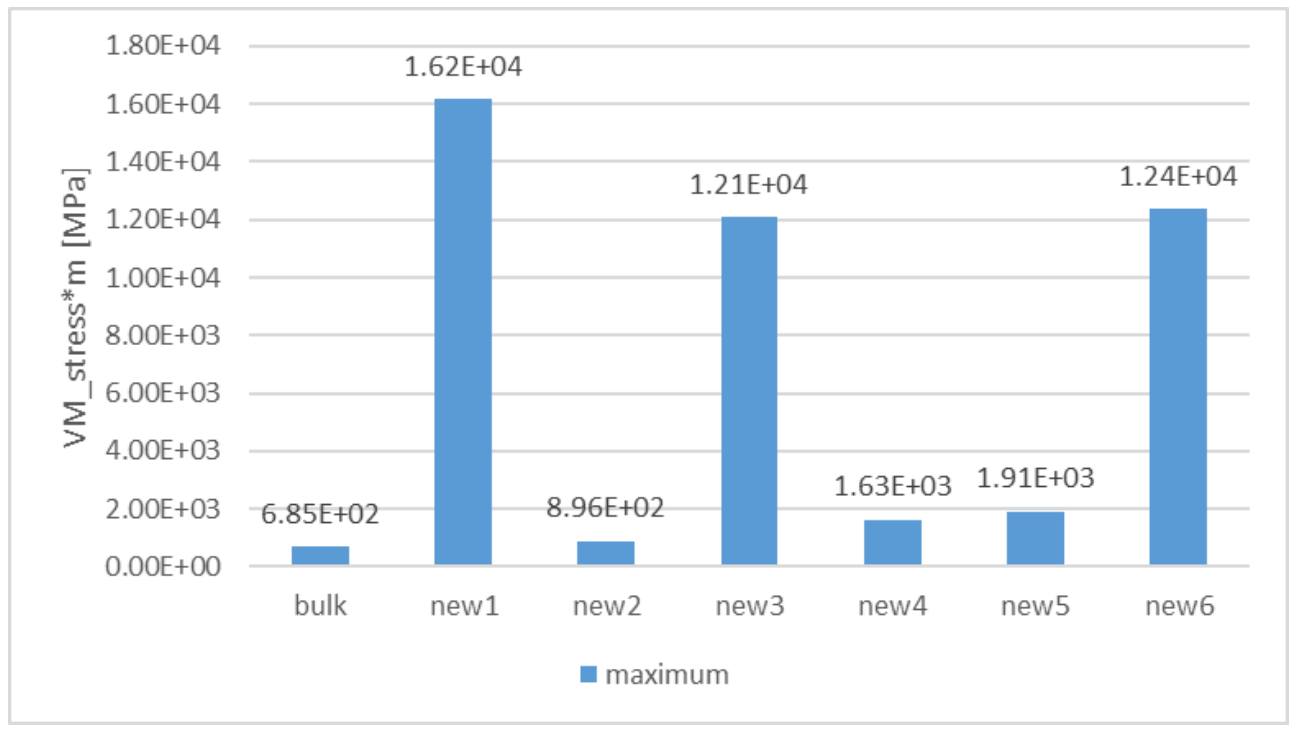

Fig. 21 - VM Stresses multiplied by the mass 


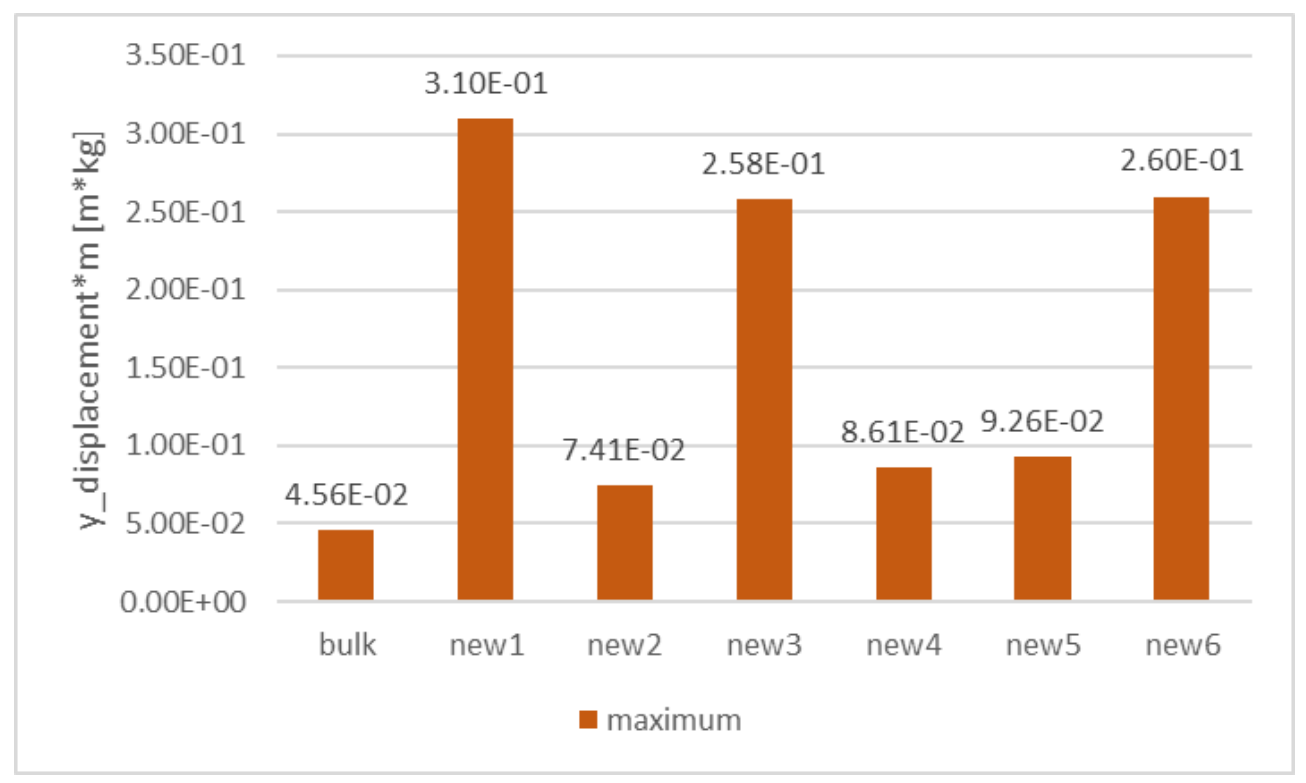

Fig. $22-Y$ displacement multiplied by the mass

From a structural point of view, as per the results of Figs. 21 and 22, none of the geometries is more effective than the bulk version. The main purpose of studying geometries with Conformal Cooling channels are the advantages from the thermal point of view, namely a reduction in the cooling time, as well as of the warpage. Nevertheless, the structural behavior must be good enough to withstand the pressure during the injection molding process. That is the main purpose of the current study.

\subsection{Relative and mass results}

As shown in the sections 4.3 and 4.2 , the results of the new geometries in comparison with the bulk geometry are relevant for the aims of the work, as well the results considering the mass. 
Therefore, the combination of both relative and mass results is also an important metric to study. This metric is represented in Eq. (24) and (25) for the resistance and stiffness behavior, respectively.

$$
\begin{aligned}
& \sigma_{m_{-} \text {rel }}=\left(\sigma_{m x}-\sigma_{m b u l k}\right) / \sigma_{m_{-} b u l k} \\
& \delta_{m_{-} r e l}=\left(\delta_{m x}-\delta_{m b u l k}\right) / \delta_{m_{-} b u l k}
\end{aligned}
$$

Figs. 23 and 24 show the Huber-Mises stresses and y deflection for all models, respectively.

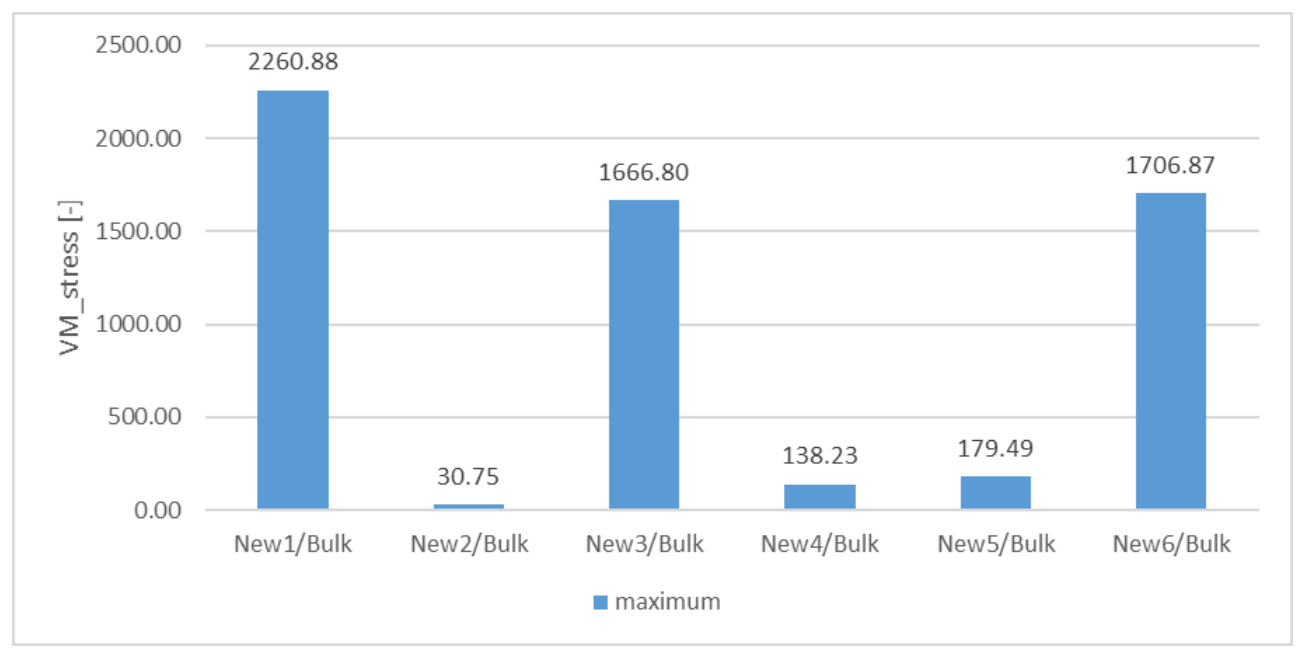

Fig. 23- Huber-Mises stresses for all models, in comparison with the Bulk model. 
It can be seen from Fig. 16 that the best geometry is the New2, showing Huber-Mises stresses only $30.75 \%$ higher than the bulk model. The worst model is New1, with a worsening of 2260.88 $\%$. Acceptable behavior can be seen in New4 and New5, whose geometries may become feasible in practical applications if a high-strength steel is used.

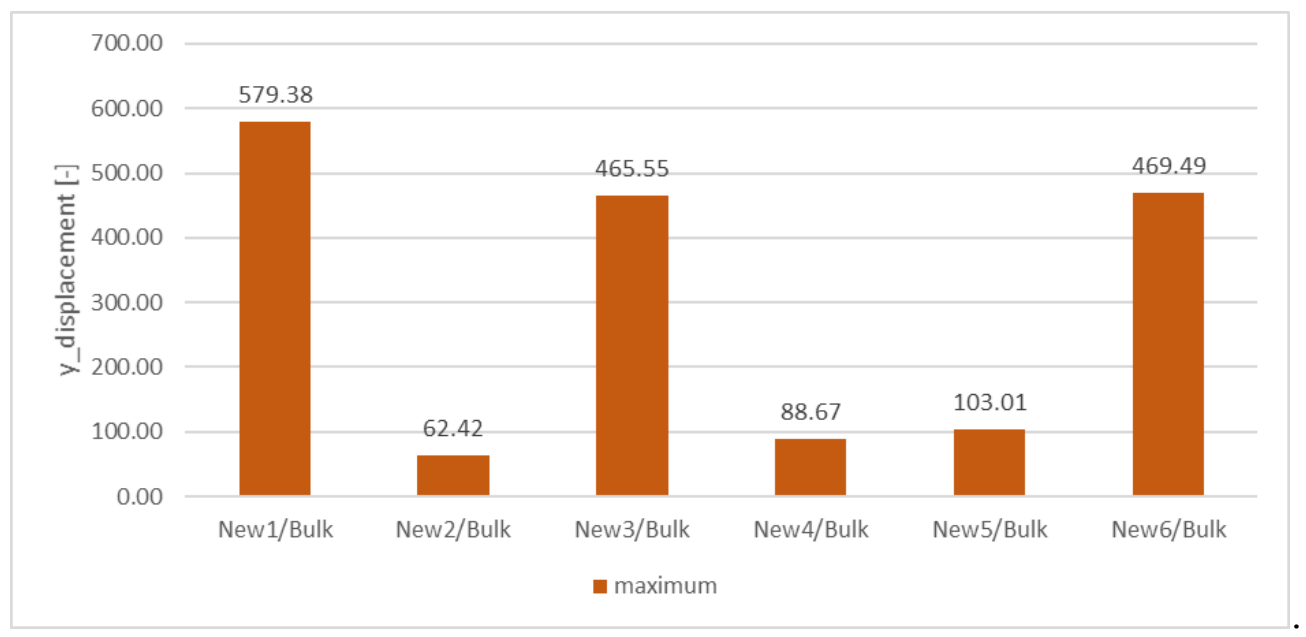

Fig. 24-y Displacement for all models, in comparison with the Bulk model.

Considering the comparison of each of the geometries with the bulk geometry with the effect of the mass, again, no geometry behaves better than the bulk one. The best geometry is the New2, once again. The geometries New4 and New5 present an interesting behavior, especially in Fig. 24, apart from the geometry New2, especially considering that the thermal analysis, to be undertaken as future work, might originate good results in any of the three geometries.

\subsection{Objective function results}


Figs. 25 shows the results of the objective function, for both resistance term, deflection term, and coupled effect. The results of Figs. 25 were obtained from Eqs. (19), (20) and (21), in terms of deflections, stresses, and combined, respectively.

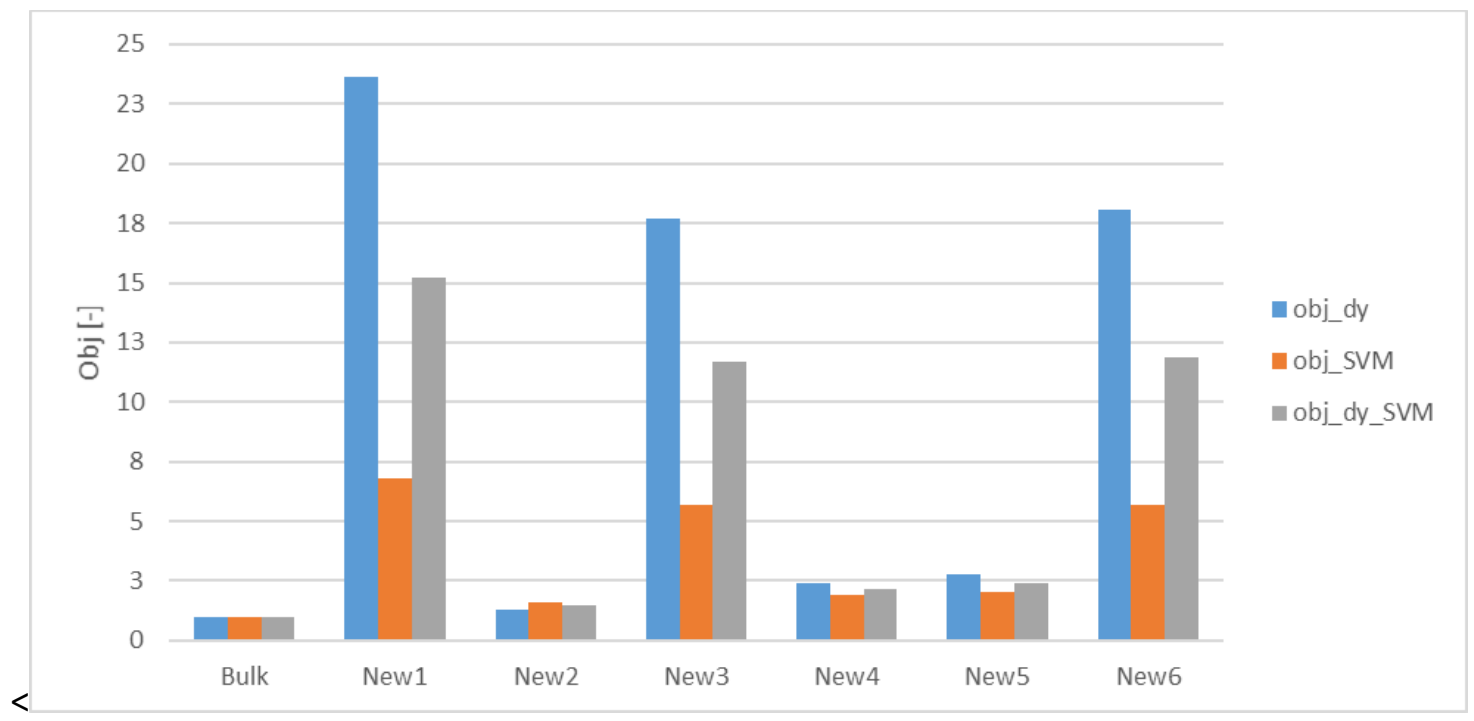

Fig. 25 -Objective criteria results

In Fig. 25, one can see that the geometries New2, New4 and New5 present an interesting behavior. These 3 geometries may be implemented in injection molds, if care is used in selecting a high-strength steel whose yield strength is high enough.

\section{Conclusions}

This work aimed to present results about the structural behavior of molds with conformal cooling channels. Although conformal cooling channels have been extensively studied in the last few years, the structural behavior is not well known. During injection molding, the mold is subjected to a significant pressure that is usually in the magnitude of the dozens of 
megapascals. Therefore, simulation of the structural behavior, by mean of static analysis is an important design tool for validating the geometry of conformal cooling channels to be applied in injection molds under working conditions. Several metrics were studied, related to the mass, stiffness and resistance behavior of the studied geometries.

The main conclusions of the work are:

-The metrics developed in this work can be applied in optimization procedures and can be used by engineers to assess the structural behavior of molds for injection machines.

-the structural behavior of the studied conformal cooling channels geometries either comply with the requirements of injection molding, either with the studied steel (P20) or would comply if a high-strength steel is used instead.

-Therefore, It can be concluded that the materials selection is an important step to be implemented in the design and calculation of injection molds, because there are commercial steels whose yield strength are high enough for the structural validation of most of the studied models to be successful, even considering a safety coefficient of 2 , which is a common one.

-The structural analysis should be complemented with design improvements/changes, as well as design optimization, in the cases where the mechanical behavior does not allow enough structural safety for practical applications.

\section{Declarations}




\section{a. Funding}

This research was supported by the Research Grant number POCI-01-0247-FEDER-024516, co-funded by the European Regional Development Fund, by the Operational Programme "Competitiveness and Internationalization", in the scope of "Portugal 2020"

\section{b. Conflicts of interest/Competing interests}

There are no declared Conflicts of interest/Competing interests

\section{c. Availability of data and material (data transparency)}

No data/results are available, as this is a review paper.

\section{d. Code availability}

Not applicable

\section{e. Ethics approval}

Not applicable

\section{f. Consent to participate}

Not applicable 


\section{g. Consent for publication}

Not applicable

\section{References}

[1] Gibson L J , Ashby M F , (1997) Cellular Solids, 2nd Edition, University of Cambridge, Cambridge University Press

[2] Meireles, J F B, (2007), "Análise dinâmica de estruturas por modelos de elementos finitos identificados experimentalmente", Ph D Thesis, University of Minho, Portugal [In Portuguese] in Silva $\mathrm{H} \mathrm{M}$, (2011), Determination of the material/geometry of the section most adequate for a static loaded beam subjected to a combination of bending and torsion, MSc Thesis, University of Minho, Portugal

[3] Dimla D, Camilotto M, Miani F (2005) Design and optimisation of conformal cooling channels in injection molding tools Journal of Materials Processing Technology, 164, 1294-1300

[4] Saifullah A, Masood S Finite element thermal analysis of conformal cooling channels in injection molding Proceedings of the 5th Australasian congress on applied mechanics, (2007)

[5] Saifullah A , Masood S Sbarski I, 2009) New cooling channel design for injection molding Proceedings of the World Congress on Engineering

[6] Gloinn T O , Hayes, C , Hanniffy, P , Vaugh K, (2007) FEA simulation of conformal cooling within injection molds International Journal of Manufacturing Research, 2, 162-170 
[7] $\mathrm{Au} \mathrm{K}, \mathrm{Yu} \mathrm{K}$ (2007) A scaffolding architecture for conformal cooling design in rapid plastic injection molding The International Journal of Advanced Manufacturing Technology, 34, 496515

[8] Wang Y, Yu K M , Wang C C, Zhang Y (2011) Automatic design of conformal cooling circuits for rapid tooling Computer-Aided Design, 43, 1001-1010 In Jahan, S A, El-Mounayri, H (2016) Optimal Conformal Cooling Channels in 3D Printed Dies for Plastic Injection Molding Procedia Manufacturing, 5, 888-900.https://doi.org/10.1016/j.promfg.2016.08.076

[9] Khan M, Afaq S K, Khan N U Ahmad S (2014) Cycle Time Reduction in Injection Molding Process by Selection of Robust Cooling Channel Design International Scholarly Research Notices

[10] Mayer S (2005) Optimised mold temperature control procedure using DMLS EOS Whitepaper, EOS, GmbH Ltd, 1-10

[11] K Au, K Yu (2014)Variable distance adjustment for conformal cooling channel design in rapid tool," Journal of Manufacturing Science and Engineering, vol 136, no 4, 044501

[12] C. Tan, D. Wang, W. Ma, Y. Chen, S. Chen, Y. Yang, K. Zhou (2020), Design and additive manufacturing of novel conformal cooling molds, Materials Design, Volume 196, 109147, ISSN 0264-1275, https://doi.org/10.1016/j.matdes.2020.109147

[13] Shen S. ,Kanbur, B B, Zhou Y , Duan F (2020), Thermal and mechanical analysis for conformal cooling channel in plastic injection molding, Materials Today: Proceedings, Volume 28, Part 2, , Pages 396-401, ISSN 2214-7853, https://doi.org/10.1016/j.matpr.2019.10.020. 
[14] Shayfull Z , Sharif S , Zain A M , Ghazali M F , Saad R M (2014) Potential of conformal cooling channels in rapid heat cycle molding: a review Advanced Polymer Technology33:21381-1-21381-24

[15] Ahn D G (2011) Applications of laser assisted metal rapid tooling process to manufacture molding and forming tools International Journal of Precision Engineering and Manufacturing 12:925-938

[16] Zheng R , Tanner R I , Fan X -J (2011) Injection molding: integration of theory and modeling methods Springer Science Business Media

[17] Park H -S , Dang X -P, (2010) Optimization of conformal cooling channels with array of baffles for plastic injection mold," International Journal of Precision Engineering and Manufacturing, vol 11, no 6, pp 879-890

[18] Meckley J , Edwards R (2009) A study on the design and effectiveness of conformal cooling channels in rapid tooling inserts," The Technology Interface Journal, vol 10, no 1, pp 1-28

[19] Feng, S , Kamat A M , Pei Y (2021) Design and fabrication of conformal cooling channels in molds: Review and progress updates, International Journal of Heat and Mass Transfer 204 124082

[20] Madenci E , Guven I. (2006), The Finite Element Method and Applications in Engineering Using ANSYS, Springer Science+Business Media, LLC

[21] shorturl at/binB3, (shortened URL), accessed on 10 of November of 2020 
[22] DIMO P20, specification DH-E68-B Edition, November of 2006, URL: shorturl at/dqswQ, (shortened URL), accessed on 10 of November of 2020

[23] Rosato D V. ,Rosato D V , Rosato M V , Editor(s), (2004)4 - INJECTION MOLDING, :Plastic Product Material and Process Selection Handbook, Elsevier, Pages 192-226, ISBN

9781856174312, https://doi.org/10.1016/B978-185617431-2/50007-4. 